\title{
Response of the middle atmosphere to CO2 doubling: results from the Canadian Middle Atmosphere Model
}

Article

Published Version

Fomichev, V. I., Jonsson, A. I., De Grandpré, J., Beagley, S. R., McLandress, C. and Shepherd, T. G. (2007) Response of the middle atmosphere to $\mathrm{CO} 2$ doubling: results from the Canadian Middle Atmosphere Model. Journal of Climate, 20 (7). pp. 1121-1144. ISSN 1520-0442 doi: https://doi.org/10.1175/JCLI4030.1 Available at https://centaur.reading.ac.uk/31788/

It is advisable to refer to the publisher's version if you intend to cite from the work. See Guidance on citing.

To link to this article DOI: http://dx.doi.org/10.1175/JCLI4030.1

Publisher: American Meteorological Society

All outputs in CentAUR are protected by Intellectual Property Rights law, including copyright law. Copyright and IPR is retained by the creators or other copyright holders. Terms and conditions for use of this material are defined in the End User Agreement. 


\section{CentAUR}

Central Archive at the University of Reading

Reading's research outputs online 


\title{
Response of the Middle Atmosphere to $\mathrm{CO}_{2}$ Doubling: Results from the Canadian Middle Atmosphere Model
}

\author{
V. I. Fomichev, ${ }^{*}$ A. I. Jonsson, ${ }^{*}$ J. de Grandpré, ${ }^{+}$S. R. Beagley, ${ }^{*}$ C. McLandress, ${ }^{\#}$ K. Semeniuk,* \\ AND T. G. SHEPHERD ${ }^{\#}$ \\ * Department of Earth and Space Science and Engineering, York University, Toronto, Ontario, Canada \\ + Department of Atmospheric and Oceanic Sciences, McGill University, Montréal, Québec, Canada \\ \# Department of Physics, University of Toronto, Toronto, Ontario, Canada
}

(Manuscript received 2 November 2005, in final form 7 July 2006)

\begin{abstract}
The Canadian Middle Atmosphere Model (CMAM) has been used to examine the middle atmosphere response to $\mathrm{CO}_{2}$ doubling. The radiative-photochemical response induced by doubling $\mathrm{CO}_{2}$ alone and the response produced by changes in prescribed SSTs are found to be approximately additive, with the former effect dominating throughout the middle atmosphere. The paper discusses the overall response, with emphasis on the effects of SST changes, which allow a tropospheric response to the $\mathrm{CO}_{2}$ forcing. The overall response is a cooling of the middle atmosphere accompanied by significant increases in the ozone and water vapor abundances. The ozone radiative feedback occurs through both an increase in solar heating and a decrease in infrared cooling, with the latter accounting for up to $15 \%$ of the total effect. Changes in global mean water vapor cooling are negligible above $\sim 30 \mathrm{hPa}$. Near the polar summer mesopause, the temperature response is weak and not statistically significant. The main effects of SST changes are a warmer troposphere, a warmer and higher tropopause, cell-like structures of heating and cooling at low and middlelatitudes in the middle atmosphere, warming in the summer mesosphere, water vapor increase throughout the domain, and $\mathrm{O}_{3}$ decrease in the lower tropical stratosphere. No noticeable change in upwardpropagating planetary wave activity in the extratropical winter-spring stratosphere and no significant temperature response in the polar winter-spring stratosphere have been detected. Increased upwelling in the tropical stratosphere has been found to be linked to changed wave driving at low latitudes.
\end{abstract}

\section{Introduction}

The observed increase in atmospheric $\mathrm{CO}_{2}$ concentrations represents the single most significant anthropogenic perturbation to the climate system. Most attention naturally focuses on the associated warming effects in the troposphere. In the middle atmosphere, the enhanced infrared emission associated with the $\mathrm{CO}_{2}$ increase acts instead to cool the region, particularly at the stratopause where the temperature maximizes. Indeed, a cooling of the middle atmosphere in recent decades has been well documented (Ramaswamy et al. 2001; Beig et al. 2003).

A major motivation for understanding the impact of increased $\mathrm{CO}_{2}$ on the middle atmosphere is that climate

Corresponding author address: V. I. Fomichev, Department of Earth and Space Science and Engineering, York University, 4700 Keele St., Toronto, ON M3J 1P3, Canada.

E-mail: victor@nimbus.yorku.ca change can potentially be easier to detect in this part of the atmosphere since the relevant physical processes are so much simpler than in the troposphere. In contrast to the troposphere, the middle atmosphere is close to being in global-mean radiative balance at all altitudes below the mesopause (e.g., Fomichev et al. 2002). Thus, global-mean temperature changes provide an excellent tool for attribution (e.g., Shine et al. 2003). Furthermore, the uncertainty in tropospheric climate change associated with cloud and water vapor feedbacks is not a major issue in the middle atmosphere. On the other hand, measurements in the middle atmosphere are subject to considerable uncertainties and are of relatively short duration [World Climate Research Programme-Stratospheric Processes and their Role in Climate (WCRP-SPARC) 2002]. Middle atmosphere climate change is also significantly affected by anthropogenically induced ozone depletion [World Meteorological Organization (WMO) 2003], which has itself acted to cool the stratosphere (Shine et al. 2003). Al-

DOI: 10.1175/JCLI4030.1 
though this last point represents a complication for attribution, it also provides a second important motivation for understanding the effects of increasing $\mathrm{CO}_{2}$ on the middle atmosphere-namely, to help distinguish the effects of ozone-depleting substances, which is a separate attribution problem.

Because ozone and temperature are so strongly coupled in the middle atmosphere, a complete understanding of middle atmosphere climate change requires accounting for the ozone radiative feedback. Furthermore, because the troposphere strongly affects the stratosphere through dynamical forcing from upwardpropagating waves, it is necessary to account for changes in this dynamical forcing. This suggests the need to use a three-dimensional coupled chemistry climate model (CCM), with an accurate representation of stratospheric ozone chemistry. A particular issue concerns the predicted effect of increased $\mathrm{CO}_{2}$ levels on the Arctic stratosphere, which has potentially significant implications for Arctic ozone (WMO 2003). Such predictions appear to be very sensitive and nonrobust. A recent comparison of several CCMs (Austin et al. 2003) found that some models predicted an increase in stratospheric wave forcing, some a decrease, and some not much of a change. Thus, there is no current consensus on even the sign of the expected $\mathrm{CO}_{2}$-induced changes in the Arctic stratosphere. While some of the differences between different models may reflect differences in the models themselves, they may also be the result of insufficiently long integrations (Butchart et al. 2000).

While the preferred tool for attribution and prediction of climate change is ensembles of transient simulations, with the different forcings included incrementally as well as together, computational constraints currently make this a severe challenge for CCMs. Thus, there is much to be learned from performing simulations under $\mathrm{CO}_{2}$-doubled conditions. Although idealized equilibrium simulations cannot reproduce the complexity of the real atmosphere, which is evolving slowly to increasing greenhouse gases, such studies can be used to identify robust processes and feedbacks that can then be used to test hypotheses in transient simulations.

It is useful to consider two distinct aspects of the middle atmosphere response to $\mathrm{CO}_{2}$ doubling - the intrinsic response and the response to the change in tropospheric climate. The former is primarily radiative photochemical in nature, driven by the $\mathrm{CO}_{2}$-induced cooling, while the latter is primarily dynamical in nature, driven by the upward-propagating waves and their induced circulation. One reason to distinguish these two aspects of the full response is that the former should be robust, while the latter can be expected to depend on details of the change in tropospheric climate, which may be more model dependent. For example, Rind et al. (2002) studied $2 \times \mathrm{CO}_{2}$ effects for two different sets of the sea surface conditions (sea surface temperatures and sea ice distribution, referred to hereafter as SSTs for short), and pointed out the importance of the SST distribution for the middle atmosphere response to doubled $\mathrm{CO}_{2}$.

Sigmond et al. (2004) separated the tropospheric and middle atmosphere effects by doubling $\mathrm{CO}_{2}$ in the troposphere and middle atmosphere separately, as well as together. They found that the combined response was equal to the sum of the separate responses, confirming the idea that the two aspects of the response are largely distinct. Schmidt et al. (2006) instead separated the radiative-photochemical and dynamical effects by controlling the SSTs. This is essentially equivalent to the Sigmond et al. (2004) approach because if only the SSTs are changed, then the middle atmosphere response to doubled $\mathrm{CO}_{2}$ is driven by the change in the troposphere alone.

In this paper, we report on $\mathrm{CO}_{2}$-doubled simulations with the Canadian Middle Atmosphere Model (CMAM). The significance of interactive ozone chemistry and photochemical analysis of the ozone radiative feedback in the CMAM under $\mathrm{CO}_{2}$-doubled conditions have been presented by Jonsson et al. (2004). To minimize the influence of tropospheric climate change on the middle atmosphere, only experiments with SSTs corresponding to $1 \times \mathrm{CO}_{2}$ conditions were used in that study. Jonsson et al. (2004) also reviewed previous 2D and 3D model studies that dealt with $\mathrm{CO}_{2}$-doubled effects in the middle atmosphere without SST changes; we refer the reader to that paper for the details. In this companion study, we discuss the overall effect of $\mathrm{CO}_{2}$ doubling in the middle atmosphere, with emphasis on the effects of SST changes.

\section{Model description and experimental setup}

CMAM is based on the Canadian Centre for Climate Modelling and Analysis (CCCma) general circulation model (GCM; see Scinocca and McFarlane 2004) and includes a comprehensive online photochemistry module in which ozone and water vapor interact with the radiation field in the model. The dynamical core and the chemistry and radiative schemes of the CMAM are described by Beagley et al. (1997), de Grandpré et al. (1997, 2000), and Fomichev et al. (2004), respectively. A detailed description of the model version used in the current study is given by Jonsson et al. (2004). The model employs a T32 spectral truncation with 65 verti- 
TABLE 1. Model simulations.

\begin{tabular}{cccc}
\hline \hline Expt & $\mathrm{CO}_{2}$ multiplier & SST changes* & Run length $(\mathrm{yr})$ \\
\hline $\mathrm{B} 1$ & 1 & None & $15+15$ \\
$\mathrm{~B} 2$ & 2 & None & $15+15$ \\
$\mathrm{C} 1$ & 1 & Yes & 15 \\
$\mathrm{C} 2$ & 2 & Yes & $15+15$
\end{tabular}

* In this paper, the term "SST" is used as a shorthand for both sea surface temperature and sea ice distribution. The SST changes are those associated with a $\mathrm{CO}_{2}$-doubled climate.

cal layers extending from the surface up to $0.00067 \mathrm{hPa}$ $(\sim 97 \mathrm{~km})$. It includes comprehensive tropospheric physics, realistic radiative schemes with inclusion of the breakdown of local thermodynamical equilibrium conditions in the mesosphere, and orographic and nonorographic gravity wave drag schemes. The photochemistry module is active from $410 \mathrm{hPa}$ up to the model lid and includes 45 species and 135 photochemical processes. A spectral advection scheme is used for the transport of long-lived constituents whereas short-lived species are treated with the standard family approach.

Four multiyear numerical experiments have been performed (Table 1). Experiment B1 is a control run for the current $\mathrm{CO}_{2}$ amount $\left(1 \times \mathrm{CO}_{2}\right)$ and $\mathrm{C} 2$ represents a $2 \times \mathrm{CO}_{2}$ experiment with the $\mathrm{CO}_{2}$ concentration in the atmosphere doubled and the SSTs prescribed for the $2 \times \mathrm{CO}_{2}$ climate. The use of prescribed SSTs is the current state of the art for middle atmosphere CCMs (Eyring et al. 2006; Austin et al. 2003). The two other experiments $(\mathrm{C} 1$ and $\mathrm{B} 2)$ represent conditions that, in fact, could not occur in the real atmosphere: $1 \times \mathrm{CO}_{2}$ with modified SSTs $(\mathrm{C} 1)$, and $2 \times \mathrm{CO}_{2}$ with unchanged SSTs (B2). These two experiments have been used to assess the impact of changes in the troposphere on the middle atmosphere. Experiments B1, B2, and C2 are referred to hereafter as the control, atmospheric $\mathrm{CO}_{2}{ }^{-}$ doubling, and combined $\mathrm{CO}_{2}$-doubling experiments, respectively. These three experiments consist of two separate 15 -yr simulations, referred to as subsets $S_{1}$ and $\mathrm{S}_{2}$ hereafter. Detailed diagnostics were only saved for subset $\mathrm{S}_{2}$. If not stated otherwise, the analysis presented in this paper is performed for the combined 30-yr datasets. For simplicity we will refer to the average of the two 15-yr simulations of a particular experiment as the 30-yr mean.

The mixing ratio of $\mathrm{CO}_{2}$ in the model is prescribed to a fixed vertical profile: it is 348 ppmv below $\sim 85 \mathrm{~km}$ and decreases above this level as described by Fomichev et al. (1998). The $\mathrm{CO}_{2}$ mixing ratio is scaled to twice its original value for the $2 \times \mathrm{CO}_{2}$ experiments. (a) DJF Sea Surface + Sea Ice Temperature Change

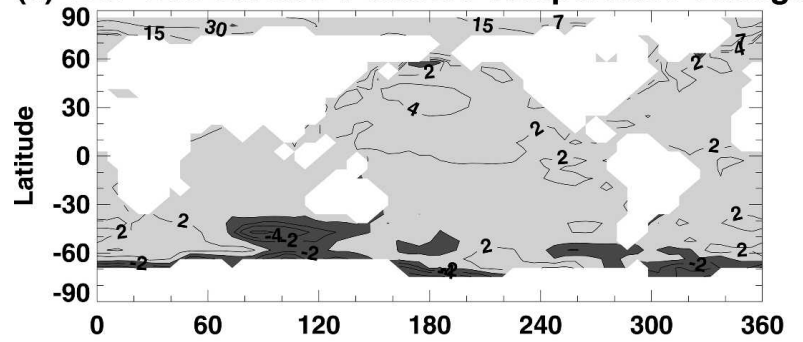

(b) JJA Sea Surface + Sea Ice Temperature Change

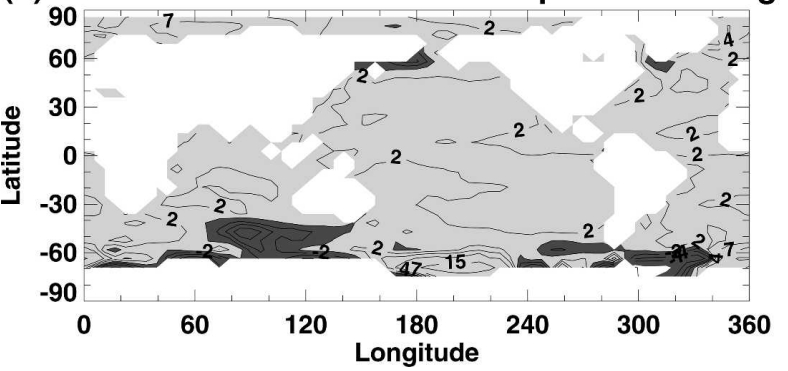

FIG. 1. Seasonal mean change in the marine surface temperature (prescribed sea surface temperature and calculated sea ice temperature) in the $2 \times \mathrm{CO}_{2}$ climate compared to the control experiment B1. (a) December-February. The large change in the Arctic reflects the fact that there is no sea ice in the $2 \times \mathrm{CO}_{2}$ climate. (b) June-August. Contours are $0, \pm 2, \pm 4, \pm 7, \pm 15$, and $30 \mathrm{~K}$. Dark shading is applied to regions with negative values.

The SST distribution for the $2 \times \mathrm{CO}_{2}$ climate has been taken from a separate transient simulation with a coupled atmosphere-ocean version of the CCCma GCM (Boer et al. 2000), which has a tropospheric component that is nearly identical to the CMAM. The SST values at the time of $\mathrm{CO}_{2}$ doubling have been used. The marine surface (sea surface and sea ice) temperature changes in the $2 \times \mathrm{CO}_{2}$ climate compared to the control experiment B1 are shown in Fig. 1 for the two solstice seasons.

\section{Control simulation and radiative forcing}

To study the model response to $\mathrm{CO}_{2}$ doubling, we have analyzed changes in temperature, ozone, and water vapor. Figures 2, 3, and 4, respectively, present 30-yr monthly mean distributions of these three fields for the control run (B1) for January and July. They provide the reference point to which the subsequent perturbation experiments will be assessed. For comparison, Figs. 2-4 also show observed climatologies derived from satellite measurements and differences between the model and observed climatologies.

The model reproduces the main characteristics of the observed climatologies, but also has some biases as dis- 

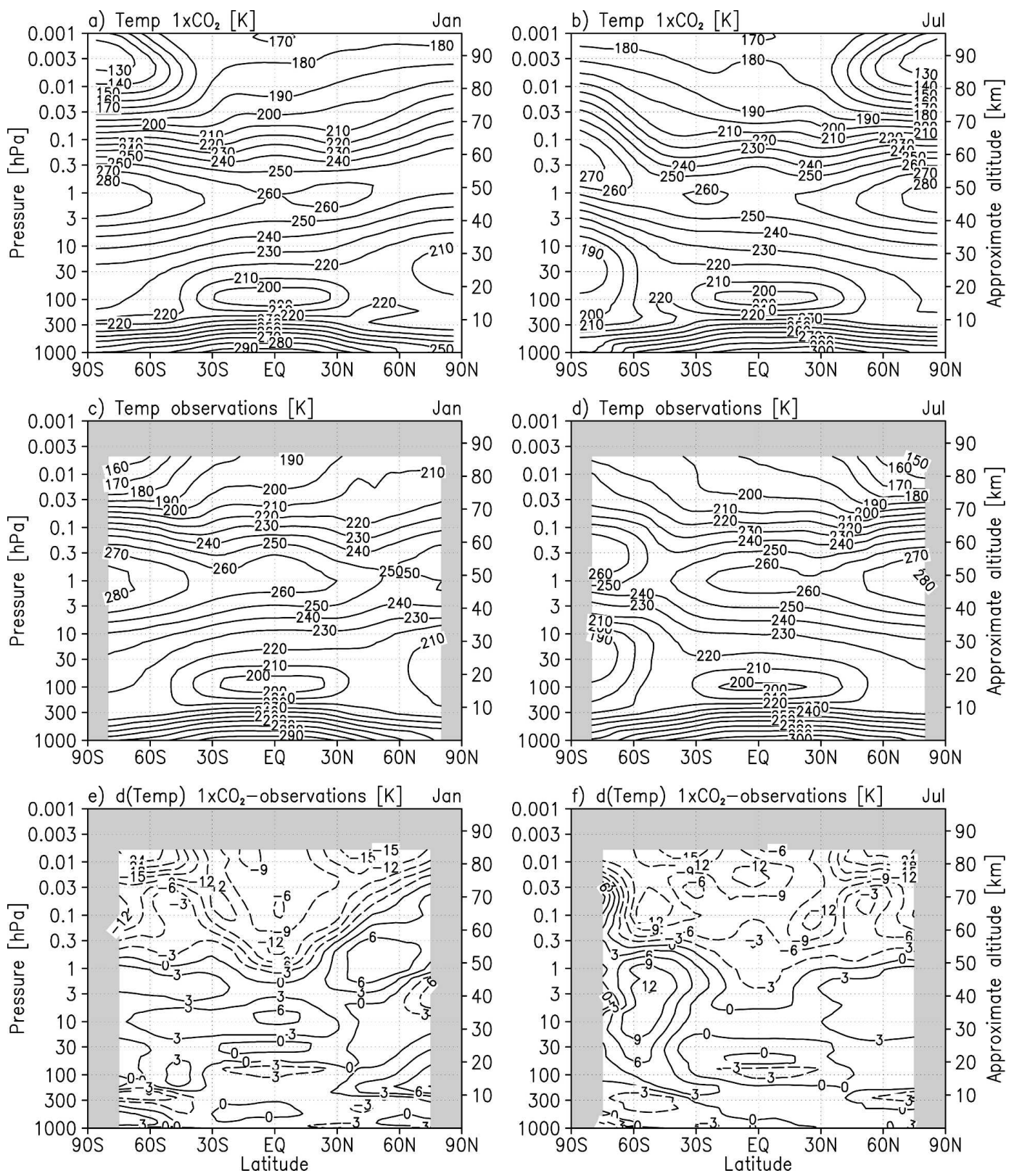

FIG. 2. Comparison of simulated and observed temperature for (left) January and (right) July. (top) Simulated zonal and monthly mean temperature $(\mathrm{K})$ averaged over $30 \mathrm{yr}$ for the $1 \times \mathrm{CO}_{2}$ case (control experiment $\mathrm{B} 1$ ). (middle) Observed climatology (K) composed of HALOE, MLS, and METO (Randel et al. 2004). (bottom) Difference (K) between the simulated and observed climatologies (negative contours are dashed). Shading indicates regions outside the range of the climatology. Contour intervals are $10 \mathrm{~K}$ for the top two rows and $3 \mathrm{~K}$ for the bottom row.

cussed below. Comparison of the temperature field (Figs. 2a,b) with a climatology composed of data from the Halogen Occultation Experiment (HALOE), the Microwave Limb Sounder (MLS), and the Met Office analyses (METO; Randel et al. 2004; Figs. 2c,d) shows agreement to within $2 \mathrm{~K}$ in the global mean throughout the troposphere and stratosphere, except for slightly too high temperatures by up to $4 \mathrm{~K}$ in the upper stratosphere (Figs. 2e,f). There is a robust and widespread cold bias throughout most of the mesosphere, which is partially attributed to the absence of both chemical and near-infrared $\mathrm{CO}_{2}$ heating in this version of the model, as discussed in Fomichev et al. (2004). Also, the summer mesopause region appears much colder in the 

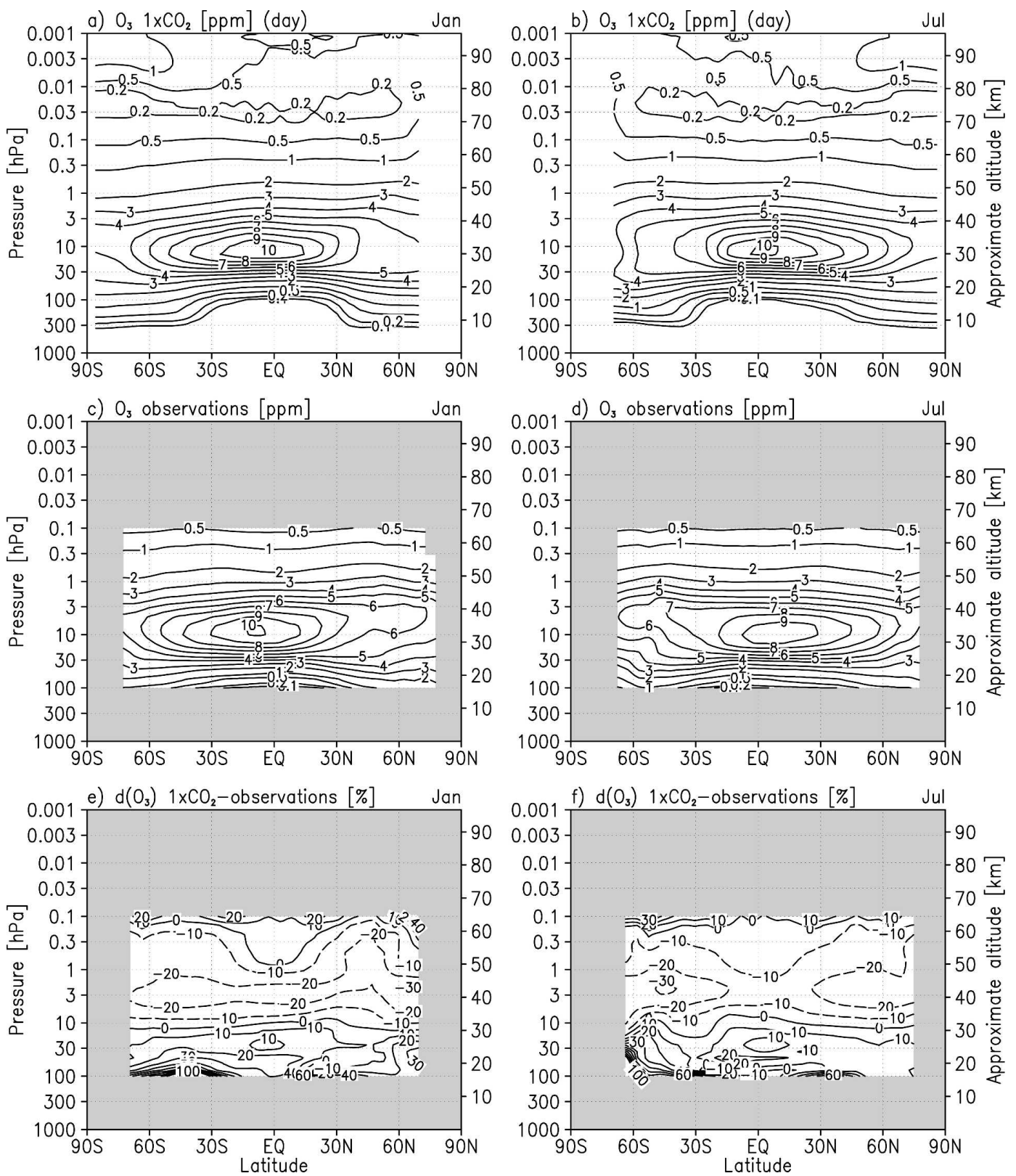

FIG. 3. Same as in Fig. 2, but for ozone. (top) Simulated zonal and monthly mean daytime ozone volume mixing ratio (ppmv) averaged over $30 \mathrm{yr}$ for the $1 \times \mathrm{CO}_{2}$ case (control experiment B1). (middle) HALOE climatology (ppmv) (Grooß and Russell 2005) at 100-0.1 hPa. (bottom) Relative difference (\%) between the simulated and observed climatologies (negative contours are dashed). Shading indicates regions outside the range of the climatology. Contour intervals are $1 \mathrm{ppmv}$ with the addition of $0.1-, 0.2-$, and 0.5 -ppmv contours for the top two rows, and $10 \%$ between $-100 \%$ and $+100 \%$ for the bottom row.

model than in the observations. It is conceivable that the model temperatures in the upper mesosphere could be affected by the proximity of the model lid. However, Fomichev et al. (2002) showed that the temperatures in the region below $\sim 90 \mathrm{~km}$ in the CMAM are nearly the same as those simulated using a version of the model with a lid at $\sim 210 \mathrm{~km}$. Furthermore, other mea- surements [e.g., the Sounding of the Atmosphere using Broadband Emission Radiometry (SABER) instrument; Mertens et al. 2004] show temperatures at the summer mesopause that are $\sim 20 \mathrm{~K}$ lower than those presented by Randel et al. (2004), in better agreement with our model results. The warm bias of up to $\sim 12 \mathrm{~K}$ in July in the stratosphere between $30^{\circ}$ and $70^{\circ} \mathrm{S}$ 

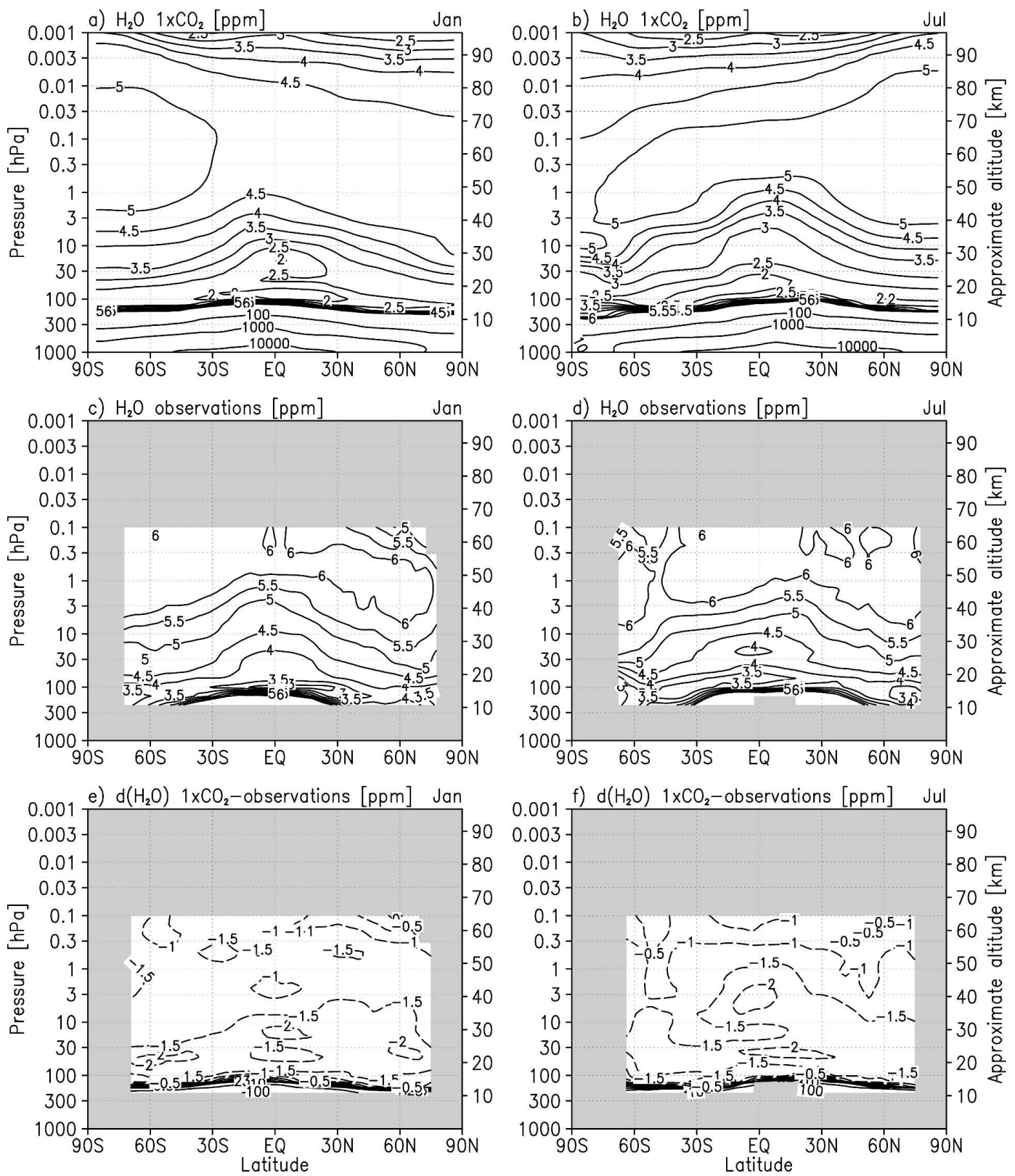

FIG. 4. Same as in Fig. 2, but for water vapor. (top) Simulated zonal and monthly mean water vapor volumemixing ratio (ppmv) averaged over $30 \mathrm{yr}$ for the $1 \times \mathrm{CO}_{2}$ case (control experiment $\mathrm{B} 1$ ). (middle) HALOE climatology (ppmv) (Grooß and Russell 2005) at 215-0.1 hPa. (bottom) Difference (ppmv) between the simulated and observed climatologies (negative contours are dashed). Shading indicates regions outside the range of the climatology. Contour intervals are 0.5 ppmv between -6 ppmv and +6 ppmv with the addition of 100-, 1000-, and 10000 -ppmv contours for the troposphere.

(Fig. 2f) is most likely a result of parameterized gravity wave drag.

Comparison of the ozone mixing ratio (Figs. 3a,b) with a climatology based on $11 \mathrm{yr}$ of HALOE observations (Grooß and Russell 2005; Figs. 3c,d) indicates a $15 \%-30 \%$ model ozone deficit in the upper stratosphere maximizing near $40 \mathrm{~km}$ (Figs. 3e,f), similar to that reported in previous versions of the model (de Grandpré et al. 2000). Diurnal variations in the ozonemixing ratio in the mesosphere prevent a useful comparison with the HALOE climatology above $50 \mathrm{~km}$. The large relative differences near $100 \mathrm{hPa}$ occur mainly in regions where ozone number densities are small. Water vapor (Figs. 4a,b) is generally biased low 

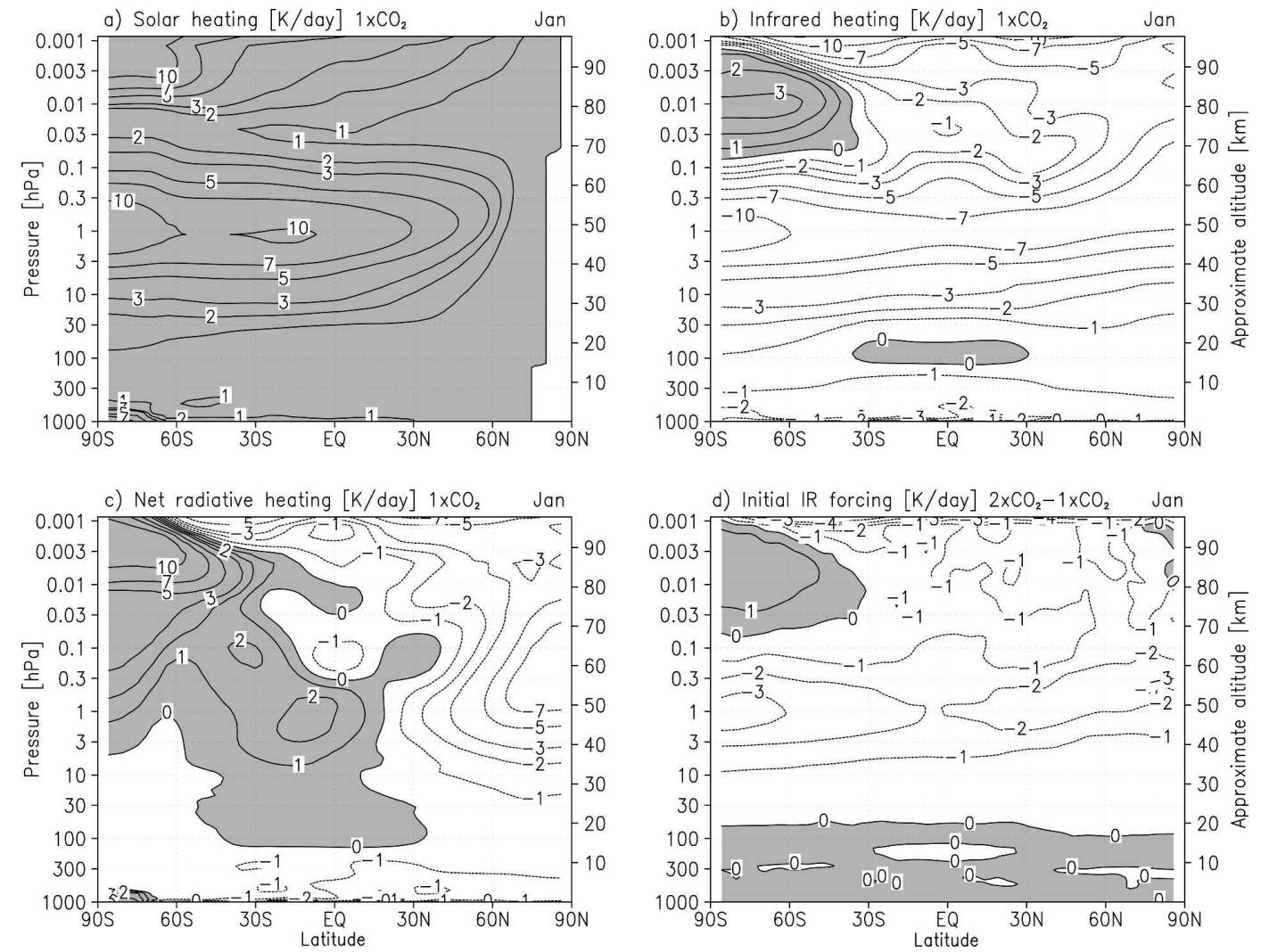

FIG. 5. Zonal and monthly mean (a) solar, (b) infrared, and (c) net (solar + infrared) radiative heating $\left(\mathrm{K} \mathrm{day}^{-1}\right)$ for the $1 \times \mathrm{CO}_{2}$ case (control experiment B1) in January averaged over $15 \mathrm{yr}$ (subset $\mathrm{S}_{2}$ ). (d) Initial infrared forcing $\left(\mathrm{K} \mathrm{day}^{-1}\right)$ induced by the $\mathrm{CO}_{2}$ doubling. Positive areas are shaded. Contours are $0, \pm 1, \pm 2, \pm 3, \pm 5, \pm 7, \pm 10$, and $\pm 15 \mathrm{~K} \mathrm{day}^{-1}$ for (a)-(c). Contour intervals are $1 \mathrm{~K} \mathrm{day}^{-1}$ for (d).

compared to observations in the middle atmosphere. The model underestimates HALOE data (Grooß and Russell 2005; Figs. 4c,d) by 1-2 ppmv in the stratosphere and lower mesosphere (Figs. 4e,f). This bias is mainly the result of excessive freeze drying resulting from too low temperatures at the tropical tropopause (near $90 \mathrm{hPa}$ in the CMAM), where the model is colder than observations (Figs. 2e,f).

The CMAM biases for temperature, ozone, and water vapor are by no means exceptional for current CCMs (Eyring et al. 2006). These biases should lead only to second-order corrections to our results since the model response depends primarily on adequate representation of the mechanisms responsible for the response, and only secondarily on the background state of the atmosphere.

Distributions of solar, infrared, and net radiative heating rates produced by the model for the $1 \times \mathrm{CO}_{2}$ case are shown in Figs. 5a-c for January. The region between the tropopause and $\sim 70 \mathrm{~km}$, except for the winter middle and high latitudes, is close to radiative equilibrium conditions [i.e., the net radiative heating (Fig. 5c) is close to zero in this region]. When $\mathrm{CO}_{2}$ is doubled in the model, this quasi-steady state is disturbed.

Figure $5 \mathrm{~d}$ shows the initial radiative forcing applied to the model upon doubling of $\mathrm{CO}_{2}$. To avoid the effects of various model feedbacks, this term is estimated as the difference between the infrared heating rates calculated for the $2 \times \mathrm{CO}_{2}$ and $1 \times \mathrm{CO}_{2}$ cases (B2 and $\mathrm{B} 1$, respectively) at the very first model time step after the $\mathrm{CO}_{2}$ concentration has been doubled. Note that use of different initial time steps would not qualitatively change the initial radiative forcing. The doubling of $\mathrm{CO}_{2}$ leads to a decrease of infrared cooling in the troposphere and, hence, provides a positive initial forcing. This forcing, along with an associated increased downward infrared flux at the surface, would lead to greenhouse warming and a warmer sea surface if the model had an interactive ocean. Near the tropical tropopause, the initial forcing enhances the positive infrared heating (Fig. 5 b) by $\sim 0.03 \mathrm{~K} \mathrm{day}^{-1}$ (i.e., by $\sim 10 \%$ of its original 

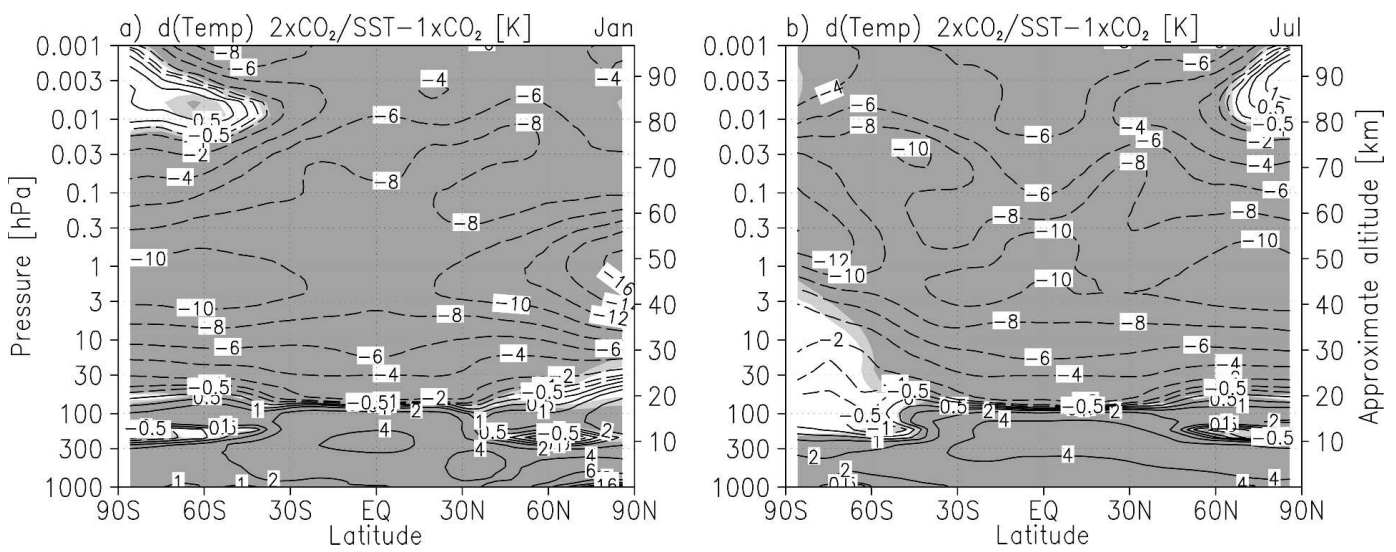

FIG. 6. Effect of $\mathrm{CO}_{2}$ doubling (experiments C2-B1) on temperature (K) for (a) January and (b) July. The data shown are zonal and monthly mean values averaged over $30 \mathrm{yr}$. Dark (light) shading: $99 \%$ (90\%) statistical significance. Contour intervals are $2 \mathrm{~K}$ with the addition of \pm 0.5 - and \pm 1 - $\mathrm{K}$ contours.

value or by $\sim 20 \%$ of the original solar heating; Fig. 5a). In the middle atmosphere, the initial forcing exhibits the same positive and negative features as the infrared heating shown in Fig. 5 b but with only $\sim 30 \%$ of the strength.

\section{Combined response to doubled $\mathrm{CO}_{2}$}

The atmosphere responds to the forcing shown in Fig. $5 \mathrm{~d}$ by changing temperature, ozone, water vapor, and other fields until the initial forcing is entirely compensated and a new quasi-equilibrium energy balance is reached. The combined response to $\mathrm{CO}_{2}$ doubling (including the associated changes in SSTs) for temperature, daytime ozone, and water vapor is shown in Figs. 6,7 , and 8 , respectively. In general, the simulated changes are statistically significant throughout most of the domain.

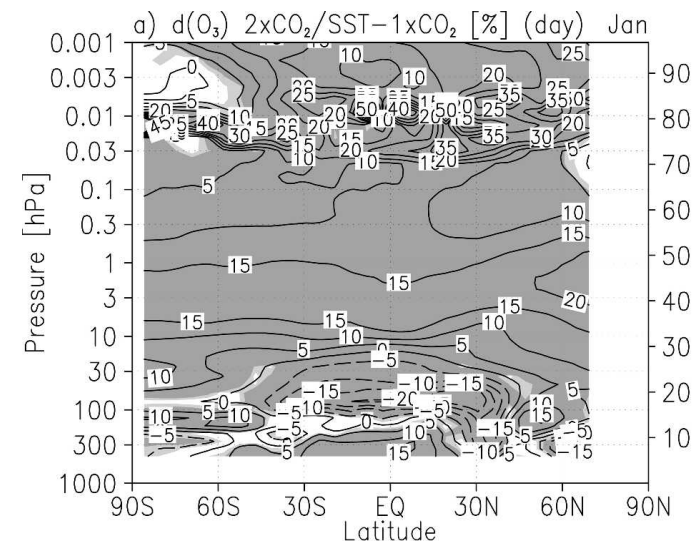

The troposphere warms by $\sim 2-4 \mathrm{~K}$ and the middle atmosphere cools by up to $\sim 10-12 \mathrm{~K}$ (Fig. 6) with a maximum impact near the stratopause. The vertical structure of the global-average thermal response in the middle atmosphere reflects the global-average background temperature distribution, with stronger cooling where temperatures are higher as expected on radiative grounds. Some latitudinal structure is also apparent. At the stratopause, there are cooling maxima at the summer pole (where temperatures are highest) and at the winter pole (where in the absence of sunlight the ozone radiative response does not counteract the cooling). Note however that polar temperatures in the winter middle atmosphere are to a large extent controlled by dynamical processes; moreover the winter pole cooling maximum from these simulations is also dependent on the model's internal variability, as will be discussed in section 6a. It is noteworthy that there is no significant

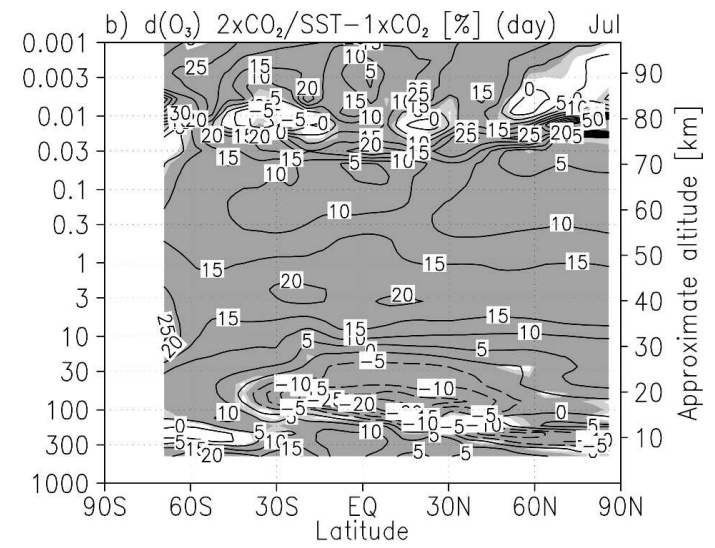

FIG. 7. Same as in Fig. 6 but showing the relative change (\%) in daytime ozone mixing ratio. Contour intervals are $5 \%$ between $-50 \%$ and $+50 \%$. 

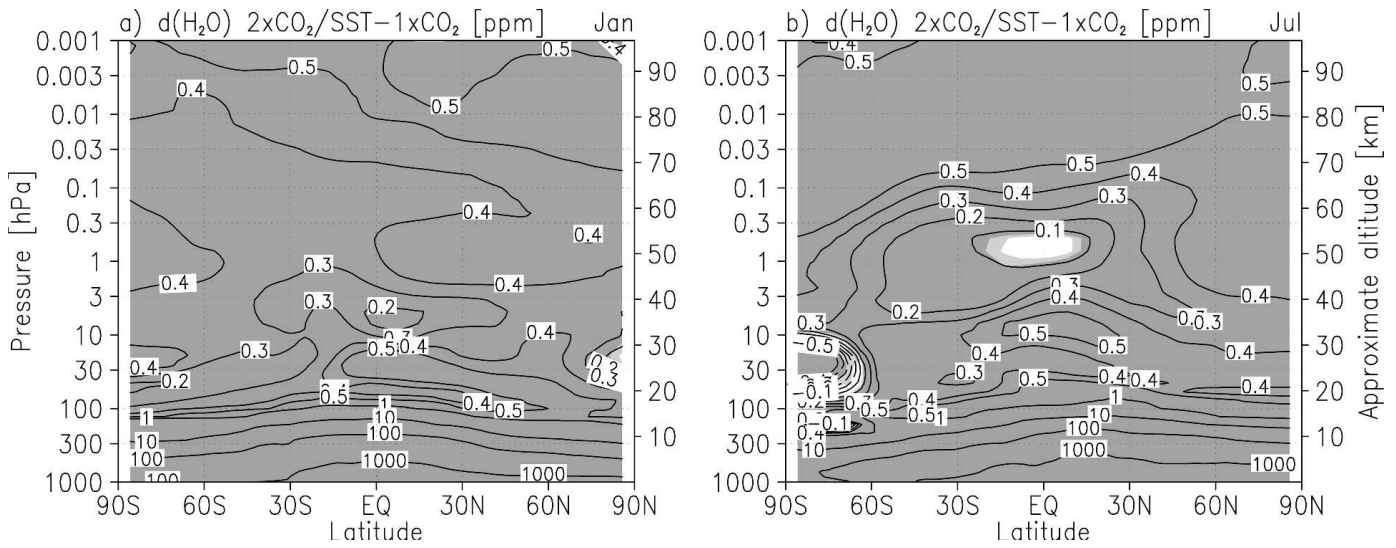

FIG. 8. Same as in Fig. 6 but showing the change in water vapor volume mixing ratio (ppmv). Contours are 0 , $\pm 0.1, \pm 0.2, \pm 0.3, \pm 0.4, \pm 0.5$, and $\pm 1 \mathrm{ppmv}$ with the addition of 10,100 , and $1000 \mathrm{ppmv}$ for the troposphere.

response near the polar summer mesopause where the initial forcing is positive (Fig. 5d). This is consistent with the fact that no noticeable trends have been observed in this region for the past few decades (Beig et al. 2003). Similar results have been achieved with the Hamburg Model of the Neutral and Ionized Atmosphere (HAMMONIA) (Schmidt et al. 2006), which has a lid at $\sim 250 \mathrm{~km}$.

The global warming predicted by the model in terms of the global-average screen (near surface) temperature change is $\sim 2.6 \mathrm{~K}$. In comparison, Cubasch et al. (2001) reported on global warming values of $1.5-4.5 \mathrm{~K}$ obtained in equilibrium $\mathrm{CO}_{2}$-doubled simulations with a range of coupled atmosphere-ocean GCMs. Notably, as a result of the prescribed SSTs in our simulations, the net radiative flux imbalance at the top of the model (which is downward) has increased by $\sim 0.9 \mathrm{~W} \mathrm{~m}^{-2}$ from the control run to the $\mathrm{CO}_{2}$-doubled case. Had the SSTs been allowed to adjust, as in the case of a coupled atmosphere-ocean simulation, they would have warmed slightly compared to the prescribed $2 \times \mathrm{CO}_{2}$ SSTs. This is what one would expect for a time-slice study of a transient process due to the considerably longer time scale required to equilibrate the ocean compared to the atmosphere. Rind et al. (2002) estimated the equilibrium climate sensitivity for doubled $\mathrm{CO}_{2}$ in the Goddard Institute for Space Studies (GISS) Global Climate/Middle Atmosphere Model (GCMAM) to be roughly $0.66 \mathrm{~K}$ for every watts per meter squared imbalance at the top of the atmosphere. Hence, a more representative estimate of the equilibrium climate sensitivity for doubled $\mathrm{CO}_{2}$ in the CMAM is $\sim 3.2 \mathrm{~K}$, which is near the middle of the range reported by Cubasch et al. (2001).

In response to the cooling of the middle atmosphere, the ozone mixing ratio increases by $10 \%-20 \%$ between 30 and $70 \mathrm{~km}$ (Fig. 7). Jonsson et al. (2004) showed that the ozone increase in this region can be understood primarily as a result of the negative temperature dependence of the $\mathrm{O}+\mathrm{O}_{2}+\mathrm{M} \rightarrow \mathrm{O}_{3}+\mathrm{M}$ reaction that controls odd oxygen partitioning. The ozone increase near $75 \mathrm{~km}$ and decrease near the tropical tropopause are mainly associated with the SST changes and will be discussed in section 6 .

The water vapor increase (Fig. 8) is mainly associated with the warmer sea surface, which allows for a warmer troposphere and, as a result, leads to a moister troposphere. The total atmospheric annual mean water vapor mass increases by $\sim 22 \%$ compared to the control experiment $\mathrm{B} 1$, whereas the relative change maximizes in the upper troposphere at $\sim 80 \%$ (see Fig. 1 in McLandress and Fomichev 2006). This is consistent with Soden et al. (2005) who, using a combination of satellite data and GCM simulations, provided convincing evidence for a moistening of the upper troposphere over the past two decades and in the future. There is also a small but statistically significant water vapor increase of $\sim 0.3-0.4 \mathrm{ppmv}$ in the stratosphere and lower mesosphere, which is caused by enhanced water vapor input from the troposphere due mainly to a warmer tropical tropopause (see section $6 \mathrm{~b}$ for further discussion).

Changes in temperature and radiatively active gases such as ozone and water vapor lead to a new quasiequilibrium energy balance. Figure 9 shows changes in the radiative energy budget induced by the $\mathrm{CO}_{2}$ doubling for January. The initial infrared forcing of up to $3 \mathrm{~K} \mathrm{day}^{-1}$ (Fig. 5d) is partially compensated by a change in infrared heating (Fig. 9b) through an adjustment of the temperature field and partially by an in- 
a) Solar heating $2 \times \mathrm{CO}_{2} / \mathrm{SST}-1 \times \mathrm{CO}_{2}[\mathrm{~K} /$ day] Jan
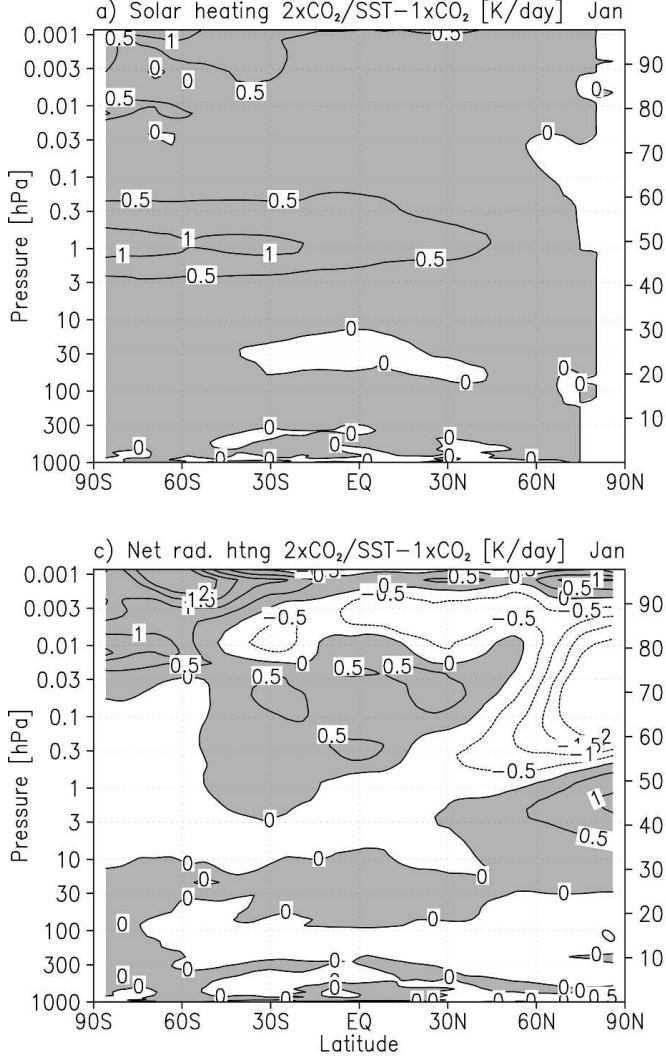

b) IR heating $2 \times \mathrm{CO}_{2} / \mathrm{SST}-1 \times \mathrm{CO}_{2}[\mathrm{~K} /$ day] Jan
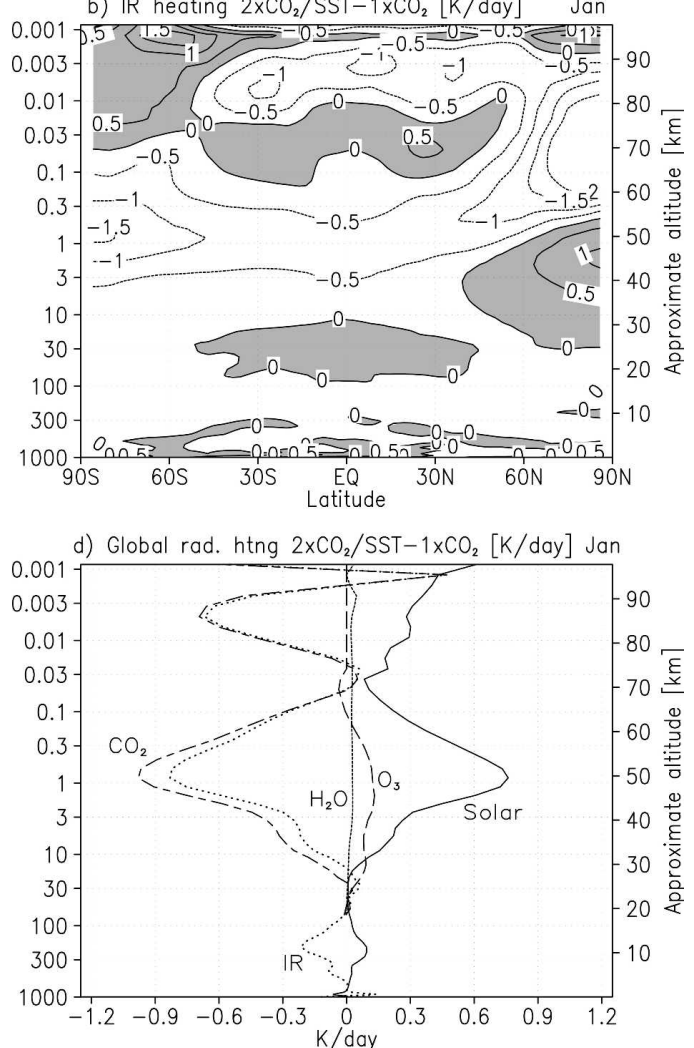

FIG. 9. Heating rate $\left(\mathrm{K} \mathrm{day}^{-1}\right.$ ) difference (experiments C2-B1) for January: (a) Solar, (b) infrared, and (c) net radiative heating. Contour intervals are $0.5 \mathrm{~K} \mathrm{day}^{-1}$. Positive area is shaded. (d) Globally averaged values: Solar, solar heating; IR, (total) infrared heating; $\mathrm{CO}_{2}, 15-\mu \mathrm{m} \mathrm{CO}$ band; $\mathrm{O}_{3}, 9.6-\mu \mathrm{m} \mathrm{O}$, band; and $\mathrm{H}_{2} \mathrm{O}$, rotational $\mathrm{H}_{2} \mathrm{O}$ band. The data shown are based on zonal and monthly mean values averaged over $15 \mathrm{yr}\left(\right.$ subset $\left.\mathrm{S}_{2}\right)$.

crease in solar heating (Fig. 9a) due to the ozone increase. The net radiative heating (Fig. 9c) is largely unchanged in the middle atmosphere below $\sim 70 \mathrm{~km}$ and south of $50^{\circ} \mathrm{N}$, indicating that the model response is radiative photochemical in this region. Figure 9d shows changes in the individual components of the globally averaged radiative energy budget. Due to strong overlapping of spectral lines in the lower atmosphere, contributions from different gases can only be isolated above $\sim 30 \mathrm{hPa}$. In this region, $\mathrm{O}_{3}$ absorption dominates the solar heating, whereas noticeable contributions to the infrared cooling are provided by the $15-\mu \mathrm{m}$ $\mathrm{CO}_{2}$, 9.6- $\mu \mathrm{m} \mathrm{O}_{3}$, and rotational $\mathrm{H}_{2} \mathrm{O}$ bands. As seen in Fig. 9 d, the residual (i.e., equilibrated) $\mathrm{CO}_{2}$ cooling is compensated not only by an increase in solar heating but also by a decrease in the 9.6- $\mu \mathrm{m} \mathrm{O}_{3}$ band cooling. Near the stratopause, the effect of the infrared $\mathrm{O}_{3}$ band exceeds $\sim 0.1 \mathrm{~K} \mathrm{day}^{-1}$ or about $15 \%$ of the change in solar heating. This is less than the radiative feedback of up to $0.4 \mathrm{~K}$ day $^{-1}$ due to the 9.6- $\mu \mathrm{m} \mathrm{O}_{3}$ band found by Akmaev and Fomichev (1998) from simulations with- out interactive chemistry. The change in the 9.6- $\mu \mathrm{m} \mathrm{O}_{3}$ band contribution can be explained by the counteracting effects of the temperature decrease and the ozone increase. The temperature decrease results in a reduction of infrared cooling, whereas the ozone increase tends to increase the 9.6- $\mu \mathrm{m} \mathrm{O}_{3}$ band cooling. Changes in the water vapor contribution to the energy budget were found to be negligible above $\sim 30 \mathrm{hPa}$, where significant increases in the water vapor abundance are compensated to a large extent by the temperature decrease.

\section{Additivity of the radiative-photochemical and dynamical responses}

To simulate the $\mathrm{CO}_{2}$-doubled climate, two forcings have been applied to the model: 1) the $\mathrm{CO}_{2}$ concentration in the atmosphere was increased and 2) the SSTs were modified to a state representative of $\mathrm{CO}_{2}$-doubled conditions. The impact of $\mathrm{CO}_{2}$ alone is mainly radiativephotochemical in the middle atmosphere, as shown by Jonsson et al. (2004), that is, the temperature changes 

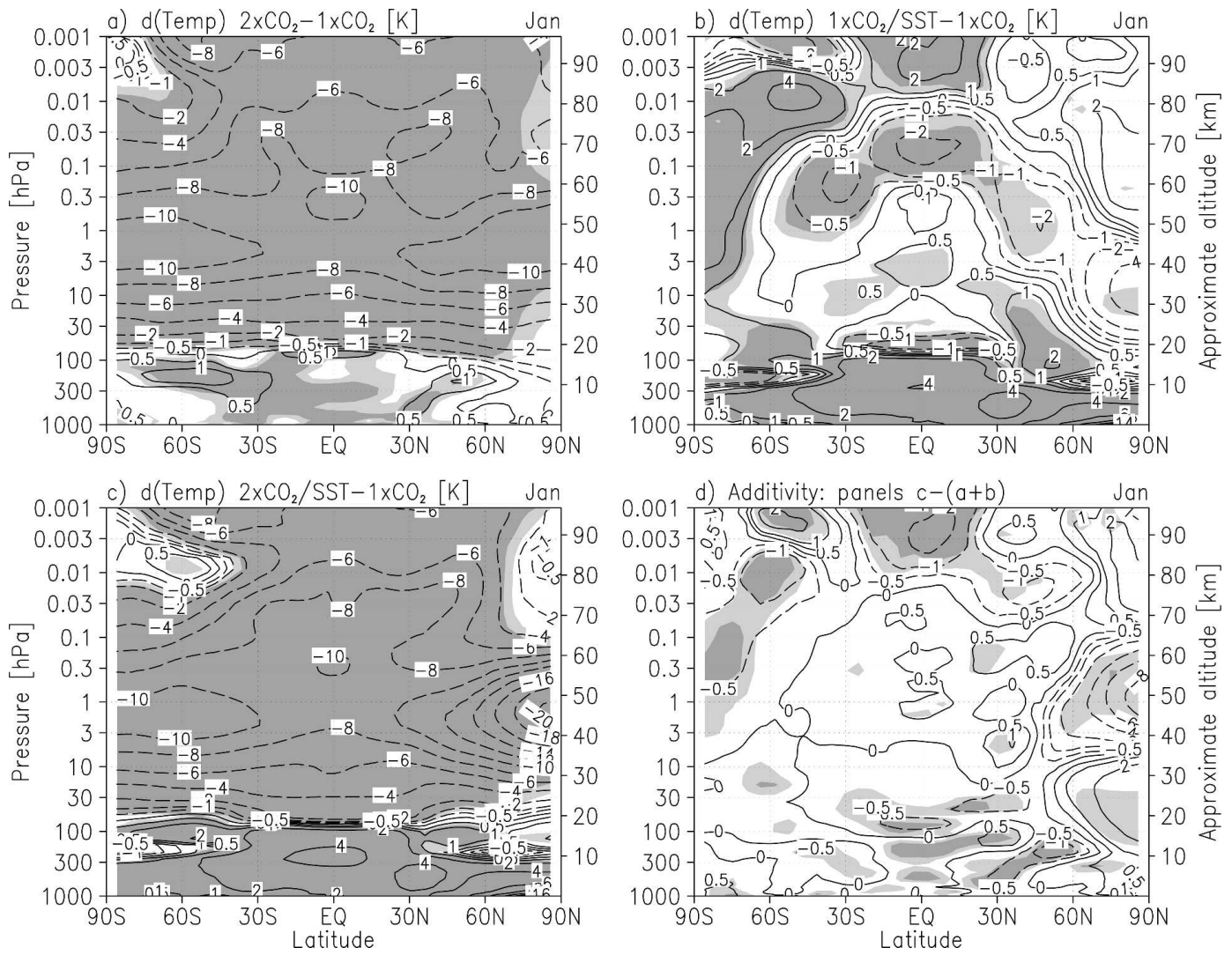

FIG. 10. Changes in the zonal and monthly mean temperature (K) for January due to (a) doubling of the atmospheric $\mathrm{CO}_{2}$ concentration (experiments B2 - B1), (b) changes in the SSTs (experiments $\mathrm{Cl}-\mathrm{B} 1$ ), and (c) combined effects of $\mathrm{CO}_{2}$ increase and SST changes (experiments $\mathrm{C} 2-\mathrm{B} 1$ ). (d) Test for additivity of the radiativephotochemical and dynamical responses \{experiments $(\mathrm{C} 2-\mathrm{B} 1)-[(\mathrm{B} 2-\mathrm{B} 1)+(\mathrm{C} 1-\mathrm{B} 1)]\}$. Dark (light) shading: $99 \%(90 \%)$ statistical significance. Values shown are 15 -yr averages (subset $\mathrm{S}_{2}$ ). Contour intervals are 2 $\mathrm{K}$ with the addition of \pm 0.5 - and $\pm 1-\mathrm{K}$ contours.

can be understood primarily as a result of $\mathrm{CO}_{2}$-induced cooling and photochemical feedback. The effect of changes in SSTs dominates in the troposphere but also produces some effects in the middle atmosphere. To analyze the impact of changes in SSTs on the middle atmosphere separately from the effect of increased $\mathrm{CO}_{2}$, the impacts of the two forcings need to be additive in this region. An analysis for additivity is presented in Fig. 10 for January using the $15-\mathrm{yr}$ subset $\mathrm{S}_{2}$. Figures $10 \mathrm{a}, \mathrm{b}$ show the individual effects of the atmospheric $\mathrm{CO}_{2}$ increase (Fig. 10a, B2 - B1) and the changes in SSTs (Fig. 10b, C1 - B1), respectively. From comparison of Figs. 10a,b, it is clear that the radiativephotochemical response dominates in the middle atmosphere. The combined effect of $\mathrm{CO}_{2}$ doubling, which includes both $\mathrm{CO}_{2}$ increase and SST changes $(\mathrm{C} 2-$ B1), is shown in Fig. 10c.

Figure 10d presents a statistical test for additivity of the radiative-photochemical and dynamical responses.
Here, the sum of the individual effects of the increase of atmospheric $\mathrm{CO}_{2}$ and the SST changes are subtracted from the combined response to $\mathrm{CO}_{2}$ doubling [i.e., $(\mathrm{C} 2$ $-\mathrm{B} 1)-[(\mathrm{B} 2-\mathrm{B} 1)+(\mathrm{C} 1-\mathrm{B} 1)]$, which we refer to as the residual]. Regions where the residual is not statistically significant indicate that additivity is a valid assumption. From Fig. 10d it is clear that this is true throughout most of the model domain. Moreover, in regions where the radiative-photochemical and dynamical responses are not additive, the magnitude of the residual is generally much smaller than the individual contribution provided by either forcings. For the middle atmosphere below $\sim 70 \mathrm{~km}$, the main region where additivity does not appear to hold is the Arctic winter stratosphere. However, we cannot draw any certain conclusions about the additivity in this region. The residual seen in Fig. 10d has only a marginal statistical significance of $90 \%$ or less and, as will be shown in section $6 \mathrm{a}, 15-\mathrm{yr}$ simulations are not sufficiently long to 

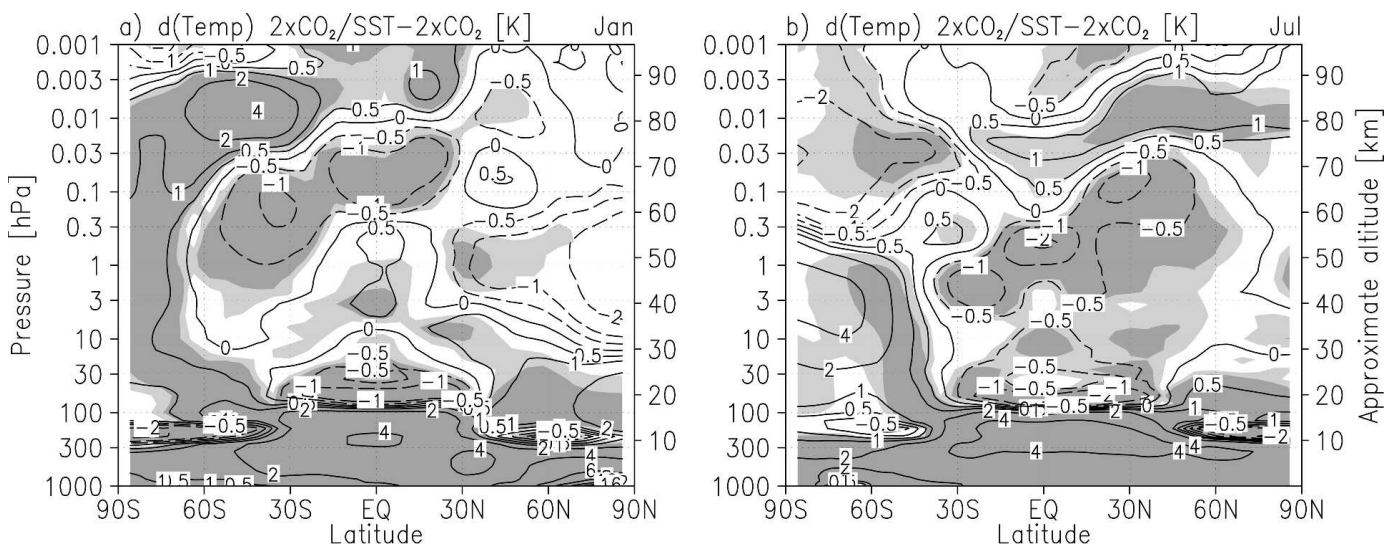

FIG. 11. Effect of changes in SSTs (experiments C2 - B2) on temperature (K) for (a) January and (b) July. The data shown are zonal and monthly mean values averaged over 30 yr. Dark (light) shading: 99\% (90\%) statistical significance. Contour intervals are $2 \mathrm{~K}$ with the addition of \pm 0.5 - and $\pm 1-\mathrm{K}$ contours.

adequately characterize the response in the Arctic winter stratosphere due to the model's internal variability. Based on the results shown in Fig. 10d, we conclude that, at least to a first approximation, the radiativephotochemical and dynamical responses are additive.

\section{Effect of the change in SSTs}

The model response to the changes in SSTs for temperature, daytime ozone, and water vapor is shown in Figs. 11, 12, and 13, respectively. In the troposphere, where convective processes dominate in establishing the overall thermal structure, a warmer sea surface inevitably leads to an increase in temperature-here by $\sim 2-4 \mathrm{~K}$ throughout most of the region (Fig. 11). The warmer sea surface implies enhanced evaporation from the oceans and, as a result, a considerable increase in the tropospheric water vapor abundance (Fig. 13). The warmer and moister troposphere in the combined experiment C2 (Figs. 6 and 8) is mainly associated with the SST changes (cf. Figs. 6 and 11, and Figs. 8 and 13).

Comparing Figs. 11a and 10b we see that the thermal responses to the SST changes are similar for $2 \times \mathrm{CO}_{2}$ and $1 \times \mathrm{CO}_{2}$ conditions. This is what one would expect if the radiative-photochemical and dynamical responses to $\mathrm{CO}_{2}$ doubling are additive. The impact of changes in SSTs on the middle atmosphere is relatively small and localized compared to the combined response. Apart from the tropospheric temperature increase, the main features outside of the polar regions are the following: cooling by $1-2 \mathrm{~K}$ in narrow regions near the extratropical tropopause and in a broader region above the tropical tropopause, warming of the midlatitude summer upper mesosphere by up to $4 \mathrm{~K}$ in January and by more than $1 \mathrm{~K}$ in July, and cell-like structures of heating
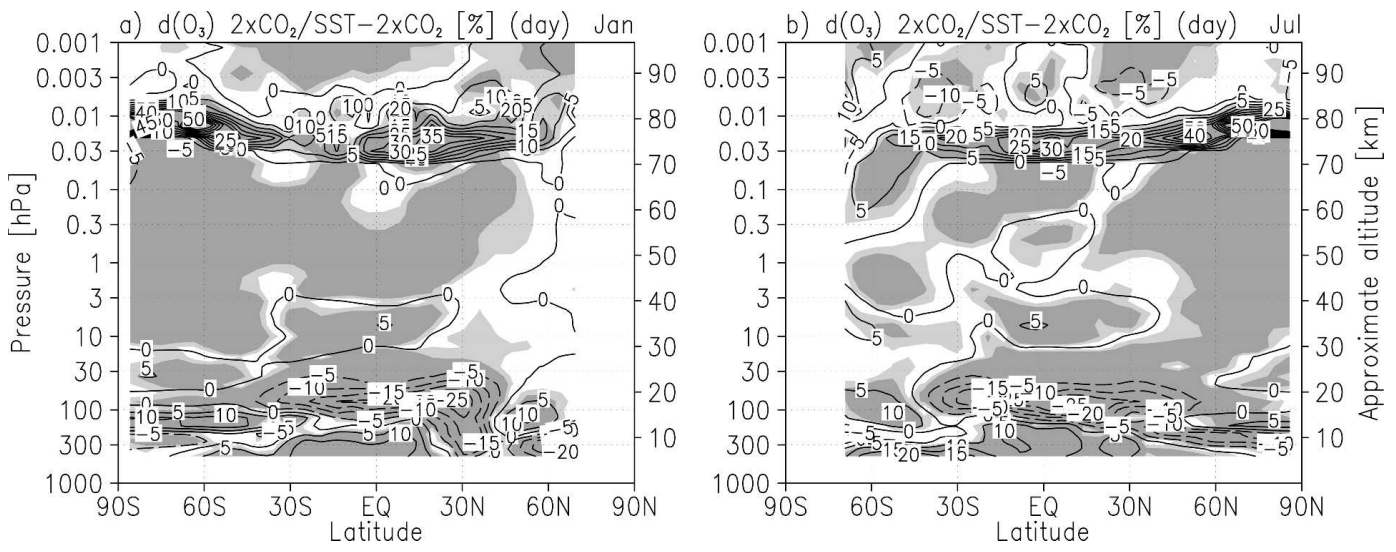

FIG. 12. Same as in Fig. 11 but showing the relative change (\%) in daytime ozone mixing ratio. Contour intervals are $5 \%$. 

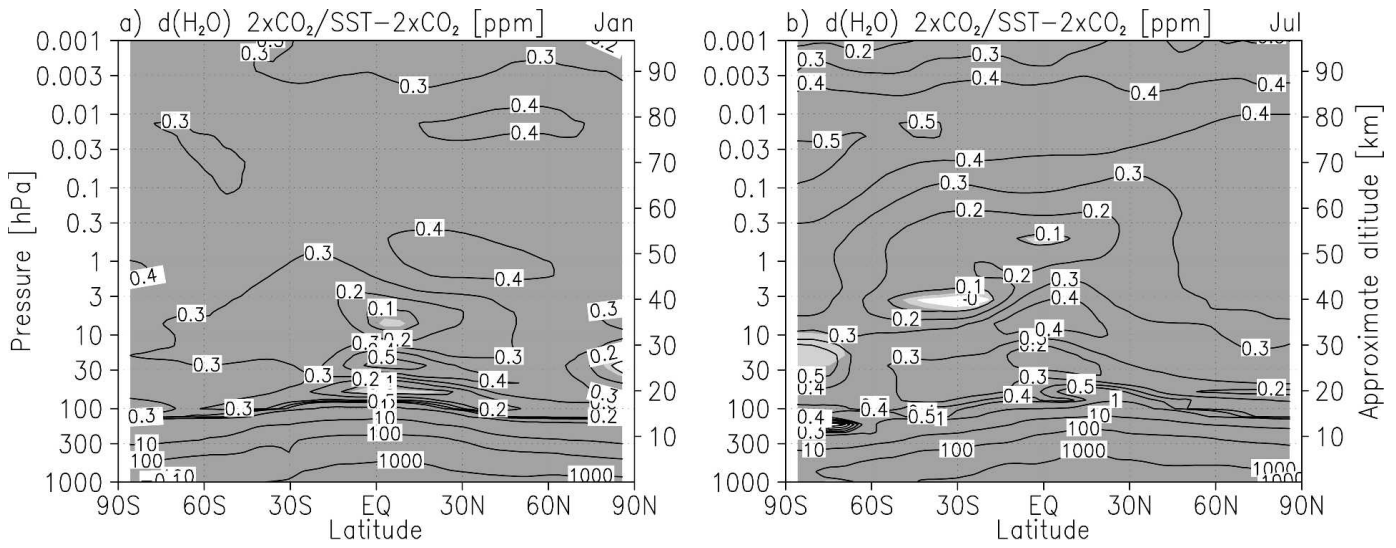

FIG. 13. Same as in Fig. 11 but showing the change in water vapor volume mixing ratio (ppmv). Contours are $0, \pm 0.1, \pm 0.2, \pm 0.3, \pm 0.4, \pm 0.5$, and $\pm 1 \mathrm{ppmv}$ with the addition of 10,100 , and $1000 \mathrm{ppmv}$ for the troposphere.

and cooling (of up to $1-2 \mathrm{~K}$ ) in the tropical and midlatitude upper stratosphere and mesosphere. All of these features agree qualitatively with results obtained by Sigmond et al. (2004) and Schmidt et al. (2006) for the middle atmosphere response to the SST changes associated with doubling of $\mathrm{CO}_{2}$. Figure 11 also shows considerable changes in the polar regions, which are generally not statistically significant or have only a marginal statistical significance of $90 \%$. Exceptions are the Southern Hemisphere (SH) summer and the Northern Hemisphere (NH) lowermost stratosphere. The model response near the tropopause and in the polar regions is discussed in detail in sections $6 \mathrm{~b}, \mathrm{c}$, respectively.

The regions of warming at middle and high latitudes in the summer mesosphere (Fig. 11) are associated with changes in the residual pole-to-pole circulation. An examination of the residual circulation of the mesosphere and upper stratosphere (not shown) reveals that the SST changes associated with doubled $\mathrm{CO}_{2}$ (experiment $\mathrm{C} 2$ ) moderate the changes in the circulation resulting from the $\mathrm{CO}_{2}$ changes alone (experiment B2). Experiment $\mathrm{B} 2$ has a generally stronger pole-to-pole flow during solstices (as compared to the control experiment B1) that results from changes in parameterized gravity wave drag (GWD) associated with changes in middle atmosphere winds. The impact of SST changes alone reduces this change in the mesosphere by slowing the summer mesospheric ascent. The regions of warming in the summer mesosphere are consistent with adiabatic heating resulting from the slower ascending branch of the residual circulation. The slower ascent also results in greater atomic oxygen concentrations in this region, which can at least partially explain the higher ozone concentration in the summer mesosphere near $75 \mathrm{~km}$ (Fig. 12). Given the long solar illumination during the polar summer, this ozone increase provides radiative heating of up to $\sim 1 \mathrm{~K} \mathrm{day}^{-1}$ (not shown), adding to the adiabatic heating associated with the slower ascent in the region.

Downward control diagnostics (Haynes et al. 1991; not shown) confirm that the changes in the residual circulation in the mesosphere are mainly due to changes in parameterized GWD. In particular, there is a slower ascent over the SH summer pole. A similar, but weaker, effect occurs in the NH summer mesosphere, which results in a weaker temperature response than for the SH counterpart (cf. Figs. 11a,b). The change in parameterized GWD is an indirect response to $\mathrm{CO}_{2}$ doubling since the parameterized gravity wave source, which is specified at the ground, remains effectively constant in all experiments. Thus, the mesospheric change in GWD is possible only through changes in the filtering of the parameterized waves by the resolved winds. The stronger equator-to-pole temperature gradient (warming in the upper tropical troposphere and cooling near the extratropical tropopause, Fig. 11) generates stronger midlatitude tropospheric westerlies (by up to $\sim 5 \mathrm{~m} \mathrm{~s}^{-1}$ at middle latitudes near $15 \mathrm{~km}$, not shown). These stronger westerlies filter more of the eastward-propagating parameterized gravity waves, which results in less eastward drag in the upper mesosphere. There is no such effect in the winter mesosphere because these waves are absorbed by the stratospheric winter westerlies. Of course, the change in gravity wave drag in the mesosphere is accompanied by a corresponding change in the lower atmosphere where the filtering occurs. However, because the lower atmosphere is much denser than the mesosphere, the impact of the enhanced low-level drag is insignificant in comparison to other forcing terms.

In reality, we can expect the gravity wave source spectrum to change under $\mathrm{CO}_{2}$-doubled conditions. 
However, given our current state of knowledge, it is not possible to predict the nature of this change. With the source spectrum essentially fixed, the gravity wave response is strongly constrained (Shepherd and Shaw 2004; Shaw and Shepherd 2007). On the other hand, we do not expect the response to be very dependent on the specific gravity wave drag parameterization used (McLandress and Scinocca 2005).

The cell-like structures above $\sim 30 \mathrm{~km}$ at low latitudes in Fig. 11 are attributed to changes in the semiannual oscillation (SAO) in the zonal mean zonal wind, which are brought about by changes in resolved equatorial waves and parameterized GWD. In response to the modified SSTs, the amplitude of the SAO between 65 and $75 \mathrm{~km}$ decreases by about $5 \mathrm{~m} \mathrm{~s}^{-1}$ from the B2 to the $\mathrm{C} 2$ experiment (results not shown), indicating that the increased SSTs are indirectly responsible. Although the exact reason for the change in the SAO is unknown, it is most likely linked to changes in upwardpropagating equatorial waves generated by the deep convection parameterization (Horinouchi et al. 2003), and possibly also to changes in the pole-to-pole meridional circulation, which contributes to the forcing of the westward phase of the oscillation. Changes to the stratopause SAO would then feed back on the parameterized GWD, producing further changes to the SAO in the mesosphere. Because of the dependence of these changes to the SAO on poorly constrained aspects of the deep convection and GWD parameterizations, the changes may very well be model dependent and consequently not reproduceable in general.

The response of the daytime $\mathrm{O}_{3}$ mixing ratio to changes in SSTs (Fig. 12), although statistically significant throughout much of the middle atmosphere, is in general very weak. Two features stand out: a decrease of up to $\sim 25 \%$ around the tropical tropopause, and a near pole-to-pole layer of up to $\sim 50 \%$ increases around $75 \mathrm{~km}$. While the relative impact on the ozone mixing ratio is large near $75 \mathrm{~km}$, the absolute changes are small as they occur in the ozone mixing ratio minimum (Fig. $3)$. Therefore these changes do not significantly modify the energy budget of the region except, as mentioned above, in the polar summer mesosphere. The ozone increases in this region result from increased downward transport of atomic oxygen from higher levels. The ozone decrease near the tropical tropopause results primarily from the upward shift of the tropopause, but also reflects an enhanced two-cell diabatic circulation in the lower stratosphere (see section $6 \mathrm{~b}$ for further analysis), as is confirmed by increased ozone mixing ratios above the tropopause in the extratropics. This change takes place well below the ozone number density peak at $\sim 25-30 \mathrm{~km}$, so column ozone changes are small, being generally below 10 Dobson units for extrapolar latitudes (not shown). Two minor features in the ozone response plots are also worth mentioning. First, the broad region of small (less than 5\%) negative changes between 40 and $70 \mathrm{~km}$ is a response to increased $\mathrm{HO}_{x}$ mixing ratios, which in turn results from increased water vapor (Fig. 13). Second, the $\sim 5 \%$ increase at $30-40$ $\mathrm{km}$ at low latitudes results partly from increased $\mathrm{O}_{2}$ photolysis caused by the ozone decrease in the layer above (so-called self-healing effect) and partly from a reduction of catalytic cycling of odd oxygen due to decreases in the $\mathrm{NO}_{x}$ abundance in the region (not shown), presumably resulting from increased tropical upwelling.

In response to the SST changes, the water vapor mixing ratio (Fig. 13) increases throughout the model domain, thus explaining most of the water vapor change in the combined experiment $\mathrm{C} 2$ (Fig. 8). There is a large increase in the troposphere and a small, but statistically significant, increase of $\sim 0.3-0.4 \mathrm{ppmv}$ in the middle atmosphere. The uniformity of the water vapor increase in the middle atmosphere suggests an enhanced inflow of water vapor from the troposphere. This is analyzed in detail in section $6 \mathrm{~b}$. The increase in tropospheric water vapor also has an indirect impact on the mesosphere through increased solar forcing of the vertically propagating diurnal tide (McLandress and Fomichev 2006).

\section{a. Importance of integration length}

An important question that arises in analysis of small signals, such as those in Figs. 11, 12, and 13, is how many years of simulation are required to confidently distinguish the signal from the internal variability of the model. This question, however, is not a trivial one to answer and a full investigation of the problem lies outside the scope of this paper. Most previous model studies have relied on 15-yr datasets or less to diagnose the middle atmosphere response to $\mathrm{CO}_{2}$ doubling. Scaife et al. (2000) argue from analysis of observations that $10 \mathrm{yr}$ are generally sufficient to characterize the mean state of the variable winter hemispheres. However, we note that the detection of a response to a small perturbation should require longer datasets, since the signal-to-noise ratio of such a problem is much smaller.

Figure 14 shows the temperature response to changes in SSTs in January for the two 15-yr subsets $\left(\mathrm{S}_{1}\right.$ and $\left.\mathrm{S}_{2}\right)$. Features away from the polar winter region that are present in the 30-yr dataset (Fig. 11a) are also present in both 15-yr subsets, indicating that these features are robust and, hence, are indeed a direct result of processes associated with changes in SSTs. For the winter polar region, however, the diagnosed temperature 

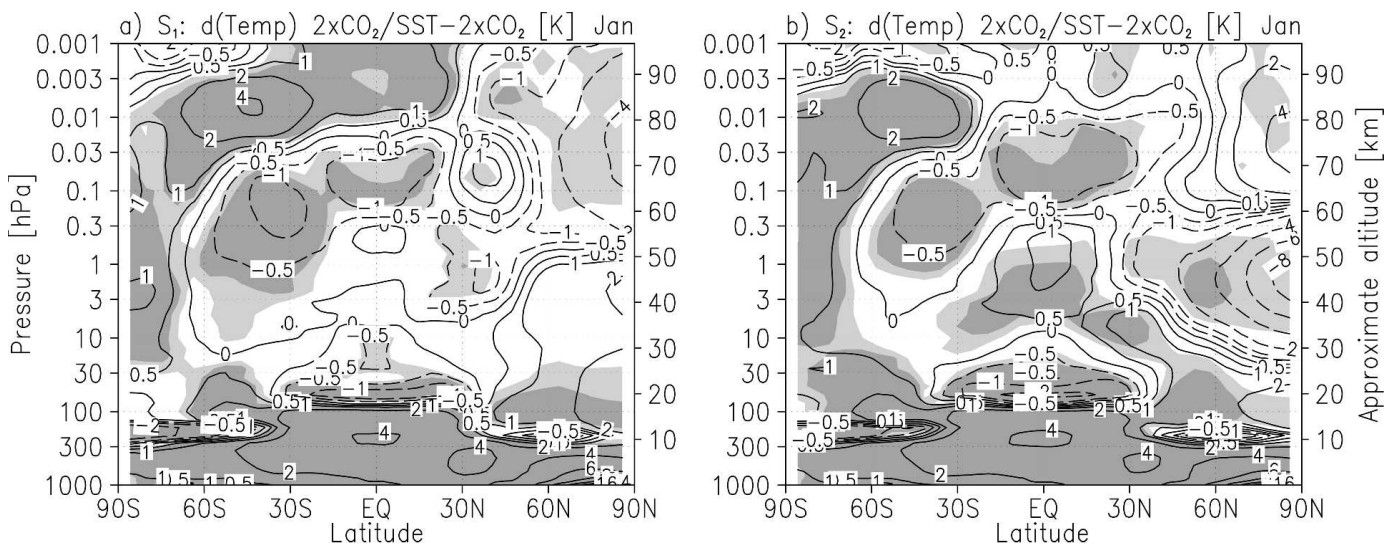

FIG. 14. Effect of changes in SSTs on temperature (K, experiments $\mathrm{C} 2-\mathrm{B} 2$ ) in January for (a) subset $\mathrm{S}_{1}$ and (b) subset $\mathrm{S}_{2}$ of the 30-yr dataset. The data shown are zonal and monthly mean values averaged over $15 \mathrm{yr}$. Dark (light) shading: $99 \%(90 \%)$ statistical significance. Contour intervals are $2 \mathrm{~K}$ with the addition of \pm 0.5 - and $\pm 1-\mathrm{K}$ contours.

changes for subsets $\mathrm{S}_{1}$ and $\mathrm{S}_{2}$ are dramatically different. Subset $\mathrm{S}_{2}$ (Fig. 14b) shows a considerable cooling throughout the middle and upper stratosphere and warming in the upper mesosphere, with both signals being statistically significant at the $90 \%$ level. Subset $S_{1}$ (Fig. 14a) shows changes of the opposite sign in the same regions, which are below the $90 \%$ significance level in most of the stratosphere and above this level in the mesosphere. The combined 30-yr dataset (Fig. 11a) shows a much smaller response that, in addition, is not statistically significant in most of the polar winter region. This implies that $15 \mathrm{yr}$ are not enough to capture the model's interannual variability in the polar winter region.

This finding is consistent with the results of Butchart et al. (2000), who found that two different 60-yr transient integrations with the same model and the same forcings (including SSTs) gave quite different changes in Arctic stratospheric temperatures: one exhibiting a statistically significant cooling at the $90 \%$ level and the other exhibiting no significant cooling. Butchart et al. (2000) noted that, as with other studies, the different trends were associated with low-frequency interannual variability and manifested in different statistics of stratospheric sudden warmings on decadal time scales. Studies with idealized models have shown the potential for internal interannual variability in the stratosphere (Scott and Haynes 2000). One likely mechanism is the "tropical flywheel" (Scott and Haynes 1998), which has a several-year time scale (Semeniuk and Shepherd 2001).

Since the response for the two subsets (Fig. 14) are indicated to have a high statistical significance $(90 \%-$ $99 \%$ ) in parts of the polar winter region, it appears that the Student's $t$ test used here may not be an appropriate tool for identifying physical changes at high latitudes. The Student's $t$ test assumes that the sampled populations (in our case series of zonally averaged monthly mean temperatures) are independent and normally distributed. It is not obvious that these assumptions are valid, particularly in the Arctic wintertime. The studies by Yoden et al. (2002) and Taguchi and Yoden (2002) indicate that temperature distributions in the polar regions may be highly skewed or even bimodal. Furthermore, in the presence of low-frequency interannual variability, the years are not statistically independent, thus violating a key assumption of the $t$ test.

Figure 15 shows the temperature distributions for the B1, B2, and C2 experiments at three different locations: the polar winter upper stratosphere (left panels), the tropical lower stratosphere (middle panels), and the midlatitude summer upper mesosphere (right panels). For each experiment and region, the means for both subsets and for the combined 30-yr dataset are indicated by the vertical lines and the arrow along the top axes. The polar upper stratosphere is clearly the most variable region of the three, with temperatures ranging over $30-50 \mathrm{~K}$. For the tropical lower stratosphere and the midlatitude upper mesosphere, the 30-yr mean temperatures are well defined and the distributions for the various experiments are in general well separated, with little overlap. For the polar upper stratosphere region, however, the 30-yr temperature distributions for the B2 and $\mathrm{C} 2$ experiments overlap over several tens of degrees and show close mean values. Consequently, the $t$ test for the 30-yr dataset shows no significant difference between $\mathrm{B} 2$ and $\mathrm{C} 2$ in this region (Fig. 11a).

Due to the limited sample sizes, it is not straightforward to attribute the shape of the 30 -yr histograms in Fig. 15 to a certain distribution law. There is, however, 

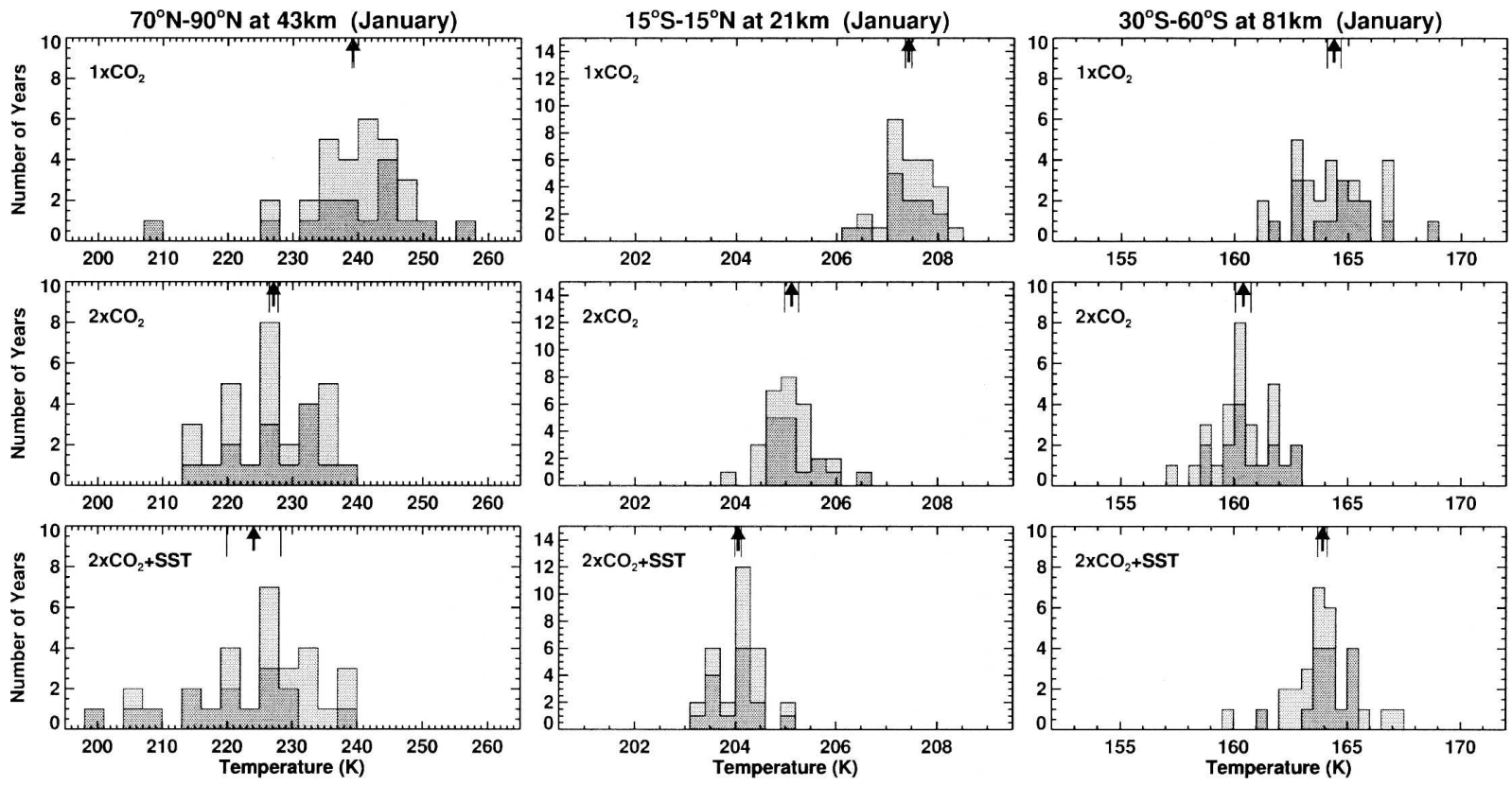

FIG. 15. Histograms of latitudinally averaged zonal mean temperature for (left) January at $70^{\circ}-90^{\circ} \mathrm{N}, 43 \mathrm{~km}$; (middle) $15^{\circ} \mathrm{S}-15^{\circ} \mathrm{N}, 21$ $\mathrm{km}$; and (right) $30^{\circ}-60^{\circ} \mathrm{S}, 81 \mathrm{~km}$ for (top row) $1 \times \mathrm{CO}_{2}$ (experiment $\mathrm{B} 1$ ); (middle row) $2 \times \mathrm{CO}_{2}$ (experiment $\mathrm{B} 2$ ); and (bottom row) $2 \times \mathrm{CO}_{2}$ with modified SSTs (experiment $\mathrm{C} 2$ ). The dark shading denotes data from the second 15-yr subset (subset $\mathrm{S}_{2}$ ); the combined light and dark shading denote the full 30-yr dataset. The arrow at the top denotes the mean of the 30-yr dataset; the two thin lines on either side are the means of the respective 15 -yr subsets.

no obvious indication that the distributions should be dramatically non-Gaussian in nature, nor can one say that the temperatures in the winter polar region are less normally distributed than those in the other two regions. Figure 15 also illustrates that the two 15 -yr subsets are characterized by their own mean and variability. In particular the mean temperature in the polar upper stratosphere in experiment C2 (Fig. 15, bottom left) differs substantially between the two subsets, explaining the opposite sign in the model temperature response in this region (Fig. 14).

\section{b. Effects on the tropopause}

The tropopause pressure and temperature were diagnosed by an interpolation scheme based on Reichler et al. (2003), but using the cold point instead of the lapse rate definition. Comparing mean changes using both variants of the diagnostic showed little difference except over the Antarctic during southern winter and spring where the cold point definition is not applicable.

A doubling of $\mathrm{CO}_{2}$ without modified SSTs (experiment B2) has a minor impact on the tropopause altitude, approximated here by the geopotential height, averaged over all months and years of the simulation (Fig. 16a, dashed curve). The tropical tropopause temperature increases by about $0.5 \mathrm{~K}$ (Fig. 16b, dashed curve). This change appears to be due primarily to the direct radiative effect of the $\mathrm{CO}_{2}$ increase. Strong overlapping of the spectral lines in the tropopause region makes it difficult to separate individual contributions of the radiatively active species, which include $\mathrm{CO}_{2}$, water
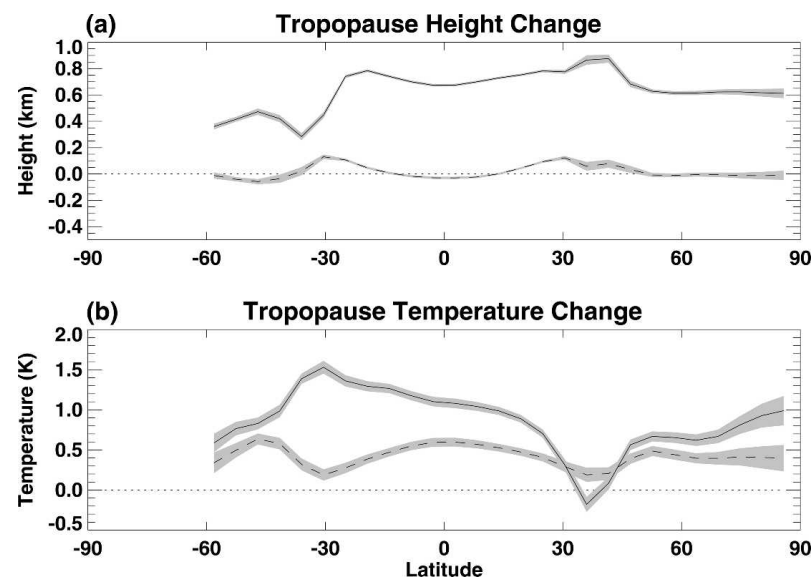

FIG. 16. Change in (a) tropopause height $(\mathrm{km})$ and $(\mathrm{b})$ tropopause temperature $(\mathrm{K})$ induced by the $\mathrm{CO}_{2}$ doubling with (solid curves, experiments $\mathrm{C} 2-\mathrm{B} 1$ ) and without (dashed curves, experiments B2-B1) changes in SSTs taken into account. The data shown are zonal and annual mean values averaged over $30 \mathrm{yr}$. The shading represents the standard error of the difference between the means. 


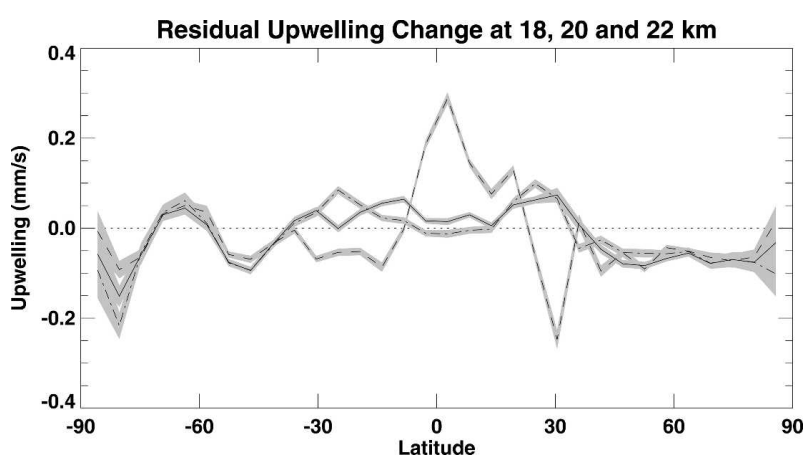

FIG. 17. Residual upwelling change induced by $\mathrm{CO}_{2}$ doubling taking changes in SSTs into account (experiments C2-B1) at 18(dash), 20- (solid), and 22-km (dash-dot) geopotential height. The data shown are zonal and annual mean values averaged over $30 \mathrm{yr}$. The shading represents the standard error of the difference between the means.

vapor, and ozone. However, the changes in water vapor and ozone near the tropical tropopause in experiment B2 (not shown) are relatively small, whereas $\mathrm{CO}_{2}$ acts as a source of both longwave and shortwave heating in the tropical tropopause region (e.g., Gettelman et al. 2004) and provides a positive initial forcing from $\mathrm{CO}_{2}$ doubling (Fig. 5d).

Inclusion of the SST changes (experiment $\mathrm{C} 2$ ) results in a significant increase of water vapor throughout most of the troposphere compared to B2 (cf. Figs. 4 and 13). The warmer sea surface increases the convective available potential energy and hence the convective activity. In this model experiment (C2) the annual and zonal mean tropopause undergoes an increase in altitude of about $700 \mathrm{~m}$ (geopotential height) in the Tropics, about $600 \mathrm{~m}$ in the $\mathrm{NH}$, and about $400 \mathrm{~m}$ in the SH extratropics (Fig. 16a, solid curve). The asymmetry between the $\mathrm{NH}$ and SH originates from the asymmetry in the SST changes between the two hemispheres, with the larger changes occurring in the NH (Fig. 1).

The mean tropical tropopause temperature increases by over $1 \mathrm{~K}$ compared to the control experiment $\mathrm{B} 1$ (Fig. 16b, solid curve), in spite of the fact that there are concurrent cooling effects. In particular, ozone decreases by about $15 \%$ at the tropopause compared to B2 (Fig. 12), and the tropical upwelling associated with the diabatic circulation increases (see Fig. 17). It is likely that additional water vapor around the tropopause increases solar heating and is also acting to trap infrared radiation, which leads to enhanced warming of the tropopause compared to B2. The water vapor increase in the lower tropical stratosphere is about twice as large as in B2 and amounts to $\sim 20 \%$ more than in the control experiment B1 (see Fig. 1 in McLandress and Fomichev 2006).
The results on the tropopause height and temperature are consistent with Seidel et al. (2001) regarding the mechanisms controlling the tropopause. Seidel et al. (2001) have shown using radiosonde data that the tropical tropopause height is mainly associated with the temperature of the underlying troposphere, whereas the tropopause temperature is associated with the temperature and pressure of the lower stratosphere.

An interesting feature of the combined experiment $\mathrm{C} 2$ is the layered water vapor structure in the tropical lower stratosphere seen in the $\mathrm{C} 2-\mathrm{B} 1$ and $\mathrm{C} 2-\mathrm{B} 2$ difference fields (Figs. 8 and 13, respectively). This reflects changes in the annual cycle of tropical tropopause temperatures. During the warm phase of the cycle more water vapor is transported into the stratosphere compared to the B1 and B2 experiments. During the cold phase ( $\mathrm{NH}$ winter) the additional water vapor is much smaller. So the difference field has a water vapor maximum moving upward from the tropopause starting in late $\mathrm{NH}$ summer and dissipating in the upper tropical stratosphere during the course of a year.

There is little difference in the tropical upwelling between B2 and the control experiment B1 (not shown). In contrast, the upwelling in the tropical lower stratosphere increases by over $10 \%$ between 16 and $20 \mathrm{~km}$ (geopotential height) in the combined experiment $\mathrm{C} 2$. Part of this increased upwelling is due to an increase in the height of the tropospheric Hadley circulation, which can be seen at $18 \mathrm{~km}$ (Fig. 17, dashed curve). At this altitude the upwelling change, which mirrors the background circulation (not shown), displays a single maximum near the equator flanked by two regions of descent. A similarly shaped upwelling change is also found at $16 \mathrm{~km}$ (not shown) but with a much larger amplitude, suggesting that it is part of the Hadley circulation. At $20 \mathrm{~km}$ (Fig. 17, solid curve) there is a broad increase of upwelling across the Tropics, with larger values occurring away from the equator, which appears to be a feature of an enhanced Brewer-Dobson circulation. At $22 \mathrm{~km}$ (Fig. 17, dash-dot curve) the upwelling change is negligible near the equator, but peaks in the subtropics of both hemispheres. This pattern is consistent with increased wave drag outside of the "tropical pipe," which would result in an upwelling increase maximizing near the tropical edge of the surf zone (Plumb and Eluszkiewicz 1999). The tropical edge of the surf zone, which corresponds to the edge of the tropical pipe, is identifiable in the model as a sharp decrease in the Eliassen-Palm (EP) flux divergence between $15^{\circ}$ and $20^{\circ}$ away from the equator in either hemisphere (not shown).

The change in the Brewer-Dobson circulation can also be seen in the seasonal evolution of tropical and 


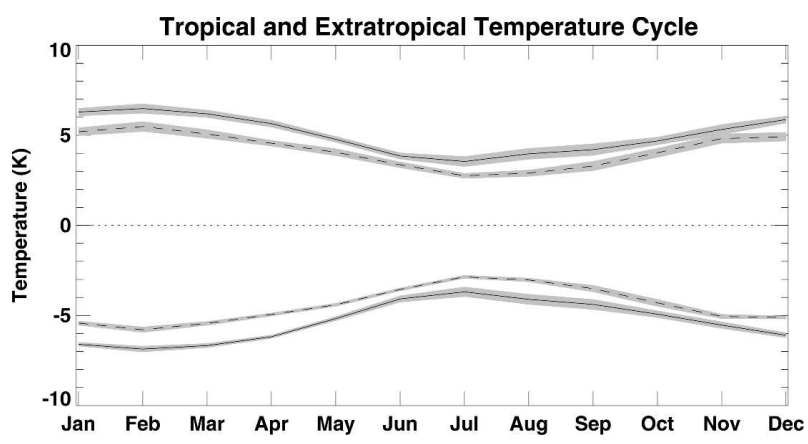

FIG. 18. Annual cycle of tropical $\left(30^{\circ} \mathrm{S}-30^{\circ} \mathrm{N}\right.$; negative curves) and extratropical (positive curves) mean temperature, with global mean subtracted, at $50 \mathrm{hPa}$ : the control experiment (B1) is denoted by dashed curves and the combined experiment $(\mathrm{C} 2$, $2 \times \mathrm{CO}_{2}$ with modified SSTs) is denoted by solid curves. The data shown are zonal and monthly mean values averaged over $30 \mathrm{yr}$. The shading represents the standard error of the mean.

extratropical temperatures at $50 \mathrm{hPa}$ (Fig. 18). Compared to $\mathrm{B} 1$, in the $\mathrm{C} 2$ experiment the tropical mean temperature is colder relative to the global mean on this pressure surface and the extratropical mean temperature is warmer, which indicates an intensification of the Brewer-Dobson circulation. The difference between B2 and B1 (not shown) is much smaller and not statistically significant. The difference between $\mathrm{C} 2$ and B1 for both the tropical and extratropical mean temperatures during the $\mathrm{NH}$ summer and fall is smaller and has a lower statistical significance than during the $\mathrm{NH}$ winter and spring: the standard error bars of the two curves nearly overlap in June and November as indicated by the shaded regions in Fig. 18. The more pronounced temperature difference during the $\mathrm{NH}$ winter and spring suggests that there is an intensification of $\mathrm{NH}$ wave drag and the associated branch of the Brewer-Dobson circulation. This is consistent with the asymmetry in the SST changes between the $\mathrm{NH}$ and $\mathrm{SH}$ (Fig. 1). An additional indication of an enhanced twocell diabatic circulation in the lower stratosphere Tropics and extratropics can be seen in the annual mean ozone distribution (ozone decreases in the tropical lower stratosphere and increases above the extratropical tropopause, Fig. 12).

Figure 19 shows the seasonal cycle of the vertical component of the EP flux $\left(F_{z}\right)$ at $45 \mathrm{hPa}$ averaged over subtropical latitudes in both hemispheres. Subtropical latitudes are chosen in order to demonstrate that it is a wave flux change in the subtropics that is responsible for the change in tropical upwelling rather than wave flux changes at higher latitudes. Since waves from either side of the equator contribute to the upwelling in the tropical lower stratosphere, the combined field is shown as well (Fig. 19c). There is some correspondence
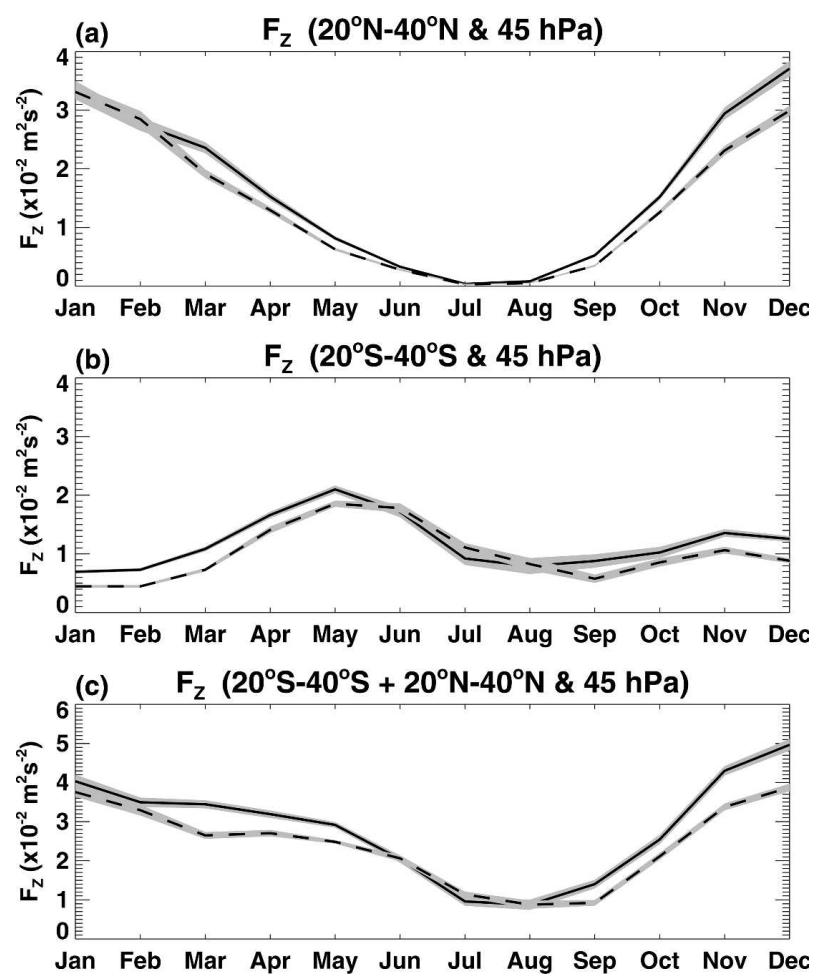

FIG. 19. Annual cycle of the vertical component of the EP flux $\left(10^{-2} \mathrm{~m}^{2} \mathrm{~s}^{-2}\right)$ at $45 \mathrm{hPa}(\sim 22 \mathrm{~km})$ for experiments $\mathrm{C} 2$ (solid, $2 \times \mathrm{CO}_{2}$ with modified SSTs) and B1 (dashed, control experiment) averaged from (a) $20^{\circ}-40^{\circ} \mathrm{N}$, (b) $20^{\circ}-40^{\circ} \mathrm{S}$, and (c) $20^{\circ}-40^{\circ} \mathrm{N}$ and $20^{\circ}-40^{\circ} \mathrm{S}$. The data shown are zonal and monthly mean values averaged over $30 \mathrm{yr}$. The shading represents the standard error of the mean. [Here $F_{z}$ is equivalent to $F_{z} /\left(a \rho_{o}\right)$ used by Andrews et al. (1987) in Eq. (3.5.3), p. 128.]

between the change from $\mathrm{B} 1$ to $\mathrm{C} 2$ in the seasonal cycle of $F_{z}$ and the change in the temperature cycle in the Tropics and extratropics (Fig. 18), in that the largest changes occur during $\mathrm{NH}$ winter and spring. While the exact cause for the increase in $F_{z}$ for the $\mathrm{C} 2$ experiment is unknown, it is possibly due to increased Rossby wave activity resulting from increased baroclinicity in the troposphere, which is consistent with previous GCM studies (Yin 2005).

Intensification of the Brewer-Dobson circulation has also been diagnosed from the mass streamfunction following Butchart and Scaife (2001). The annual mean tropical upwelling mass flux on the 70-hPa surface increases by $1.22 \pm 0.06 \mathrm{Tg} \mathrm{s}^{-1}$ in $\mathrm{C} 2$ from $7.36 \pm 0.03 \mathrm{Tg}$ $\mathrm{s}^{-1}$ in $\mathrm{B} 1$ (the range represents the standard error of the 30-yr dataset). This agrees well with the average increase of $1.1 \pm 0.2 \mathrm{Tg} \mathrm{s}^{-1}$ found by Butchart et al. (2006) in a comparison of time slice and transient simulations from most of the current middle atmosphere GCMs. 

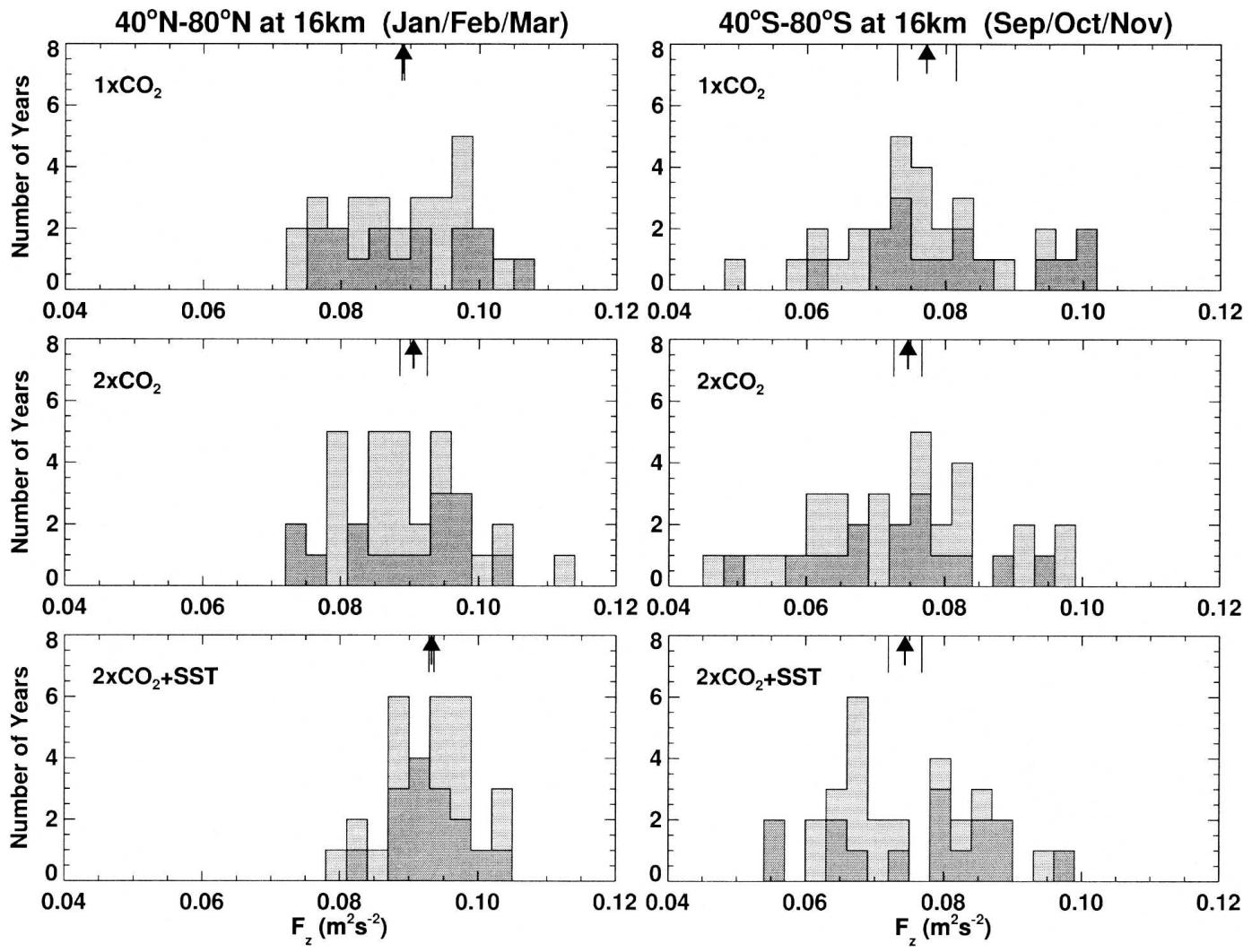

FIG. 20. Histograms of the latitudinally averaged vertical component of the EP flux $\left(\mathrm{m}^{2} \mathrm{~s}^{-2}\right)$ at $16 \mathrm{~km}$ for (left) January-March from $40^{\circ}-80^{\circ} \mathrm{N}$ and (right) September-November from $40^{\circ}-80^{\circ} \mathrm{S}$ for $1 \times \mathrm{CO}_{2}$ (experiment B1, top row), $2 \times \mathrm{CO}_{2}$ (experiment B2, middle row), and $2 \times \mathrm{CO}_{2}$ with modified SSTs (experiment $\mathrm{C} 2$, bottom row). The dark shading denotes data from the second 15-yr subset (subset $S_{2}$ ); the combined light and dark shading denote the full 30-yr dataset. The arrow at the top denotes the mean of the 30-yr dataset; the two thin lines on either side are the means of the respective 15-yr subsets. [Here $F_{z}$ is equivalent to $F_{z} /\left(a \rho_{o}\right)$ used by Andrews et al. (1987) in Eq. (3.5.3), p. 128.]

\section{c. Planetary Rossby waves in the extratropical stratosphere}

A question of obvious importance to the stratospheric circulation and polar temperatures is the extent to which the forcing from extratropical planetary Rossby waves propagating out of the troposphere will change with doubled $\mathrm{CO}_{2}$ and modified SSTs. This dynamical feedback to the radiative changes could in principle aggravate, mitigate, or even reverse the stratospheric cooling expected on radiative grounds. Austin et al. (2003) identified this process as a key uncertainty in future predictions of Arctic ozone, with not even the sign of the changes being clear. Figure 20 shows histograms of the vertical component of the EP flux $\left(F_{z}\right)$ averaged from $40^{\circ}$ to $80^{\circ}$ at $100 \mathrm{hPa}(\sim 16 \mathrm{~km})$ for the months when the breakup of the polar vortex occurs. As with the temperature histograms shown in Fig. 15, the combined 30-yr dataset is denoted by the total shaded area. The differences in the time mean $F_{z}$ in the SH for the 30-yr datasets (denoted by the arrows) are statistically insignificant (the significance level is below $80 \%$ ). While the difference between the $\mathrm{B} 1$ and $\mathrm{C} 2$ experiments in the $\mathrm{NH}$ is significant at the $95 \%$ level, the relative change is small (less than $5 \%$ ). Thus, in these experiments, we are unable to detect a large change in the flux of planetary waves into the stratosphere in middle and high latitudes. An analysis of the mechanisms responsible for the response we find in CMAM is beyond the scope of this paper. A detailed analysis of the processes involved is given by Rind et al. (2005).

A useful means of highlighting the relationship between stratospheric planetary wave forcing and polar temperatures in the lower stratosphere was proposed by Newman et al. (2001). Figure 21 shows such a result 
(a)

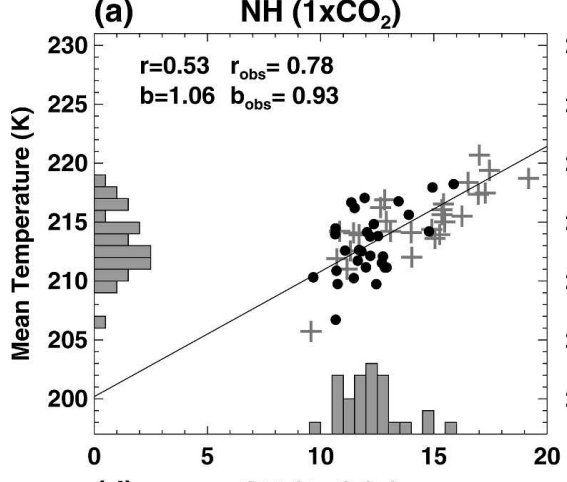

(d) $\mathrm{SH}\left(1 \mathrm{xCO}_{2}\right)$

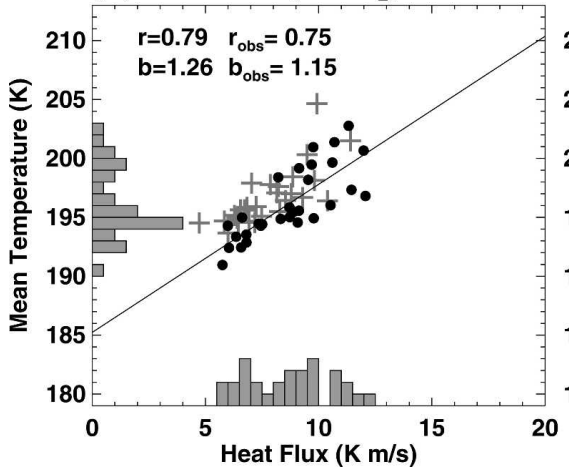

(b)

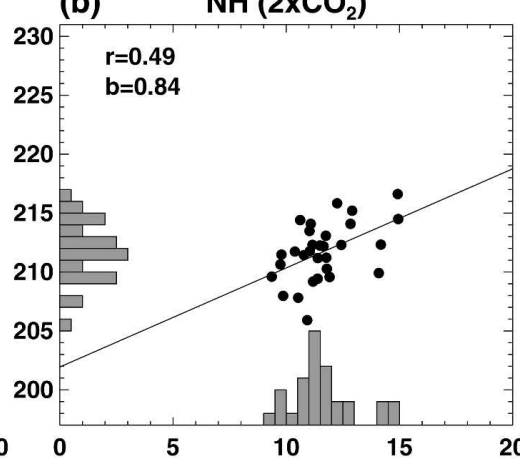

(e) $\mathrm{SH}\left(2 \times \mathrm{CO}_{2}\right)$

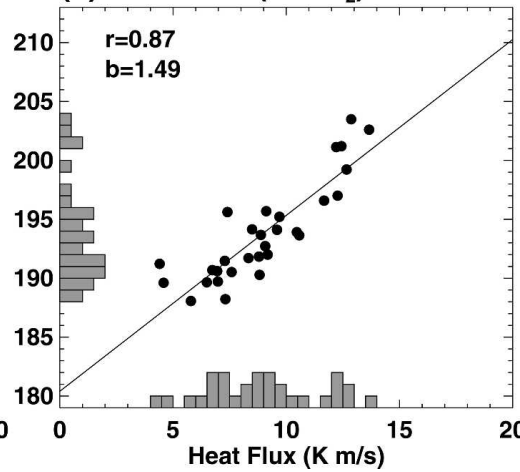

(c)

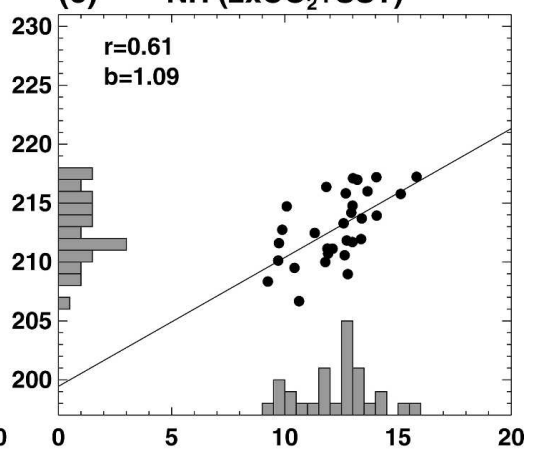

(f) $\mathrm{SH}\left(2 \times \mathrm{CO}_{2}+\mathrm{SST}\right)$

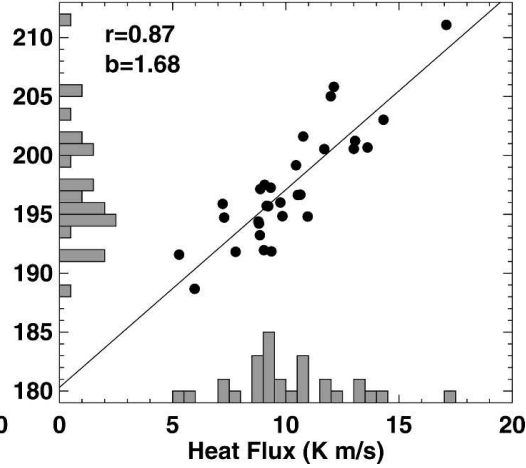

FIG. 21. Scatterplots of heat flux $\left(\overline{v^{\prime} T^{\prime}}\right)$ at $100 \mathrm{hPa}(\sim 16 \mathrm{~km})$ vs zonal mean temperature $(\bar{T})$ at $50 \mathrm{hPa}(\sim 21 \mathrm{~km})$. (top row) NH for the three 30-yr datasets: (a) $1 \times \mathrm{CO}_{2}$ (experiment B1), (b) $2 \times \mathrm{CO}_{2}$ (experiment B2), and (c) $2 \times \mathrm{CO}_{2}$ with modified SSTs (experiment $\mathrm{C} 2$ ). Here $\overline{v^{\prime} T^{\prime}}$ is for January-February and is averaged from $40^{\circ}$ to $80^{\circ} ; \bar{T}$ is for February-March and is averaged from $60^{\circ}$ to the pole. (bottom row) Same as (top row) but for the SH, where $\overline{v^{\prime} T^{\prime}}$ (multiplied by -1 ) and $\bar{T}$ are for July-August and August-September, respectively. The straight line is the linear best fit through the points. The correlation coefficient $(r)$ and the slope of the best-fit line (b) are plotted in the top-left corner. Histograms of the distributions of $\overline{v^{\prime} T^{\prime}}$ and $\bar{T}$ are shown along the horizontal and vertical axes, respectively. The plus marks denote the observations taken from the NCEP-NCAR reanalysis-2 dataset for the years 1979-2005; the corresponding correlation coefficient and slope of the best-fit line (not drawn) are denoted by the subscript "obs."

but using the months, pressure levels, and latitude ranges employed in Figs. 4 and 5 of Austin et al. (2003). Overall there is good qualitative agreement between the observations and the $1 \times \mathrm{CO}_{2}$ (experiment $\mathrm{B} 1$ ) results, which gives us confidence in the ability of the CMAM to simulate this aspect of the stratospheric circulation. Note that when the zonal mean temperatures at levels higher than $50 \mathrm{hPa}$ are used, the correlation with the 100-hPa heat flux decreases. Manzini et al. (2003) illustrated the utility of this diagnostic for separating the radiative and dynamical aspects of stratospheric climate change; radiative changes correspond to a shift in the intercept of the straight line fit with the vertical axis, which we denote $\bar{T}_{\text {pole }}(0)$ and which represents the combined effects of radiation and gravity wave drag, while changes in large-scale dynamical forcing correspond to changes in the location of the points along this line. Similarly with Manzini et al. (2003), we find the relationship between resolved wave forcing and polar temperatures to be much better de- fined in the $\mathrm{SH}$ than in the $\mathrm{NH}$. Thus, we focus on the $\mathrm{SH}$.

If we compare Figs. 21e and 21f we do not see a noticeable change in $\bar{T}_{\text {pole }}(0)$, which is consistent with the fact that $\mathrm{CO}_{2}$ has not changed between these two simulations. However, comparing these $2 \times \mathrm{CO}_{2}$ results to those in Fig. 21d for the $1 \times \mathrm{CO}_{2}$ case, we see a change in $\bar{T}_{\text {pole }}(0)$ of several degrees. The sign of the temperature change is in agreement with the cooling that occurs in the stratosphere that results from increased $\mathrm{CO}_{2}$. The robustness of this change in $\bar{T}_{\text {pole }}(0)$ is in contrast to the high degree of variability in this region of the atmosphere and the fact that our 30-yr dataset is probably not long enough to accurately determine the means, as seen by the histograms of $\overline{v^{\prime}} T^{\prime}$ and $\bar{T}_{\text {pole }}$ shown along the horizontal and vertical axes in Fig. 21. This shows that process-oriented diagnostics such as this wave drag-temperature relation may provide a more reliable attribution of atmospheric change than individual fields. 


\section{Summary and conclusions}

The Canadian Middle Atmosphere Model (CMAM) has been used to study the effects of $\mathrm{CO}_{2}$ doubling on the middle atmosphere. The radiative-photochemical impact on the atmosphere has already been studied by Jonsson et al. (2004). In this companion paper we have presented the overall effect of $\mathrm{CO}_{2}$ doubling on the middle atmosphere, with an emphasis on analyzing the impacts produced by changes in the troposphere.

Four different model experiments have been performed. In addition to a control run and a $\mathrm{CO}_{2}$-doubled experiment with sea surface conditions (i.e., sea surface temperatures and sea ice distribution, referred to as SSTs for short) representative of a $\mathrm{CO}_{2}$-doubled climate, a $\mathrm{CO}_{2}$-doubled experiment without changes in SSTs, and an experiment with modified SSTs but with unchanged $\mathrm{CO}_{2}$ were also performed. The latter two experiments, which are physically unrealizable, were performed to examine the relative impact on the middle atmosphere of radiative-photochemical effects and effects produced by modified SSTs (and hence a modified tropospheric climate). Our results show that to a first approximation the radiative-photochemical impact and the response to SST changes are additive and therefore can be analyzed separately.

Analysis of the radiative energy budget has shown that in response to $\mathrm{CO}_{2}$ doubling the net radiative heating remains largely unchanged in the middle atmosphere below $\sim 70 \mathrm{~km}$, except poleward of $\sim 50^{\circ}$ in the winter hemisphere. This reflects the radiative-photochemical nature of this region of the atmosphere. Dynamical effects occur mainly in the upper mesosphere and also over the winter pole. The initial forcing induced by $\mathrm{CO}_{2}$ doubling is partially compensated by a change in infrared cooling through an adjustment of the temperature field, and partially by an increase in heating associated with ozone changes. The ozone radiative feedback occurs through both an increase in solar heating and a decrease in the 9.6- $\mu \mathrm{m}$ band cooling, with the latter providing up to $15 \%$ of the total effect. Changes in the water vapor contribution to the radiative balance, which appear to be a dominant component in the troposphere and also important in the lower stratosphere, are negligible above $\sim 30 \mathrm{hPa}$ on a globally averaged basis.

For the case of $\mathrm{CO}_{2}$ doubling with SST changes taken into account, the troposphere warms by $\sim 2-4 \mathrm{~K}$ and the middle atmosphere cools by up to $\sim 10-12 \mathrm{~K}$. There is no significant response near the polar summer mesopause, in accordance with observations over the past few decades (Beig et al. 2003). This is the result of a combination of opposite effects. The $\mathrm{CO}_{2}$ radiative forcing is positive in this region (due to the heat exchange between this cold region and the relatively warm layers below), but the doubling of $\mathrm{CO}_{2}$ also leads to a strengthening of the summer-to-winter circulation in the mesosphere, with stronger upwelling over the summer pole, which produces adiabatic cooling and mitigates the positive radiative forcing near the mesopause.

Much of the temperature change in the middle atmosphere can be understood in terms of the radiativephotochemical response. The impact of SST changes on middle atmospheric temperatures are generally localized and smaller in amplitude. The main impacts are the following: 1) a warmer and higher tropopause during all seasons, 2) cooling near and above the tropopause by up to $1-2 \mathrm{~K}, 3$ ) warming of the middle latitude summer upper mesosphere by up to $4 \mathrm{~K}$ in January and by more than $1 \mathrm{~K}$ in July, and 4) cell-like structures of heating and cooling (of up to 1-2 K) alternating with height in the tropical and middle latitude upper stratosphere and mesosphere.

The increased height of the tropopause is clearly attributed to SST changes, while the warming of the tropopause results from enhanced radiative heating in the lower stratosphere. The narrow regions of cooling near the extratropical tropopause are due to a vertical shift of the local temperature minimum at the tropopause. In the Tropics the region of cooling is broader both latitudinally and vertically (extending into the lower stratosphere) and is mainly attributed to adiabatic cooling resulting from enhanced upwelling in the tropical branch of the Brewer-Dobson circulation. The latter appears to be due to enhanced wave drag at low latitudes.

The higher temperatures at middle and high latitudes in the summer upper mesosphere result from decreased adiabatic cooling associated with a slower ascending branch of the mesospheric residual circulation. This change is caused by weakened westerly gravity wave drag in the summer hemisphere that results from enhanced critical level filtering of eastward-propagating waves by the strengthened tropospheric westerlies. The cell-like structures of heating and cooling at low latitudes reflect a change in the vertical structure of the semiannual oscillation (SAO). It is important to note, however, that both the warmer summer mesosphere and the SAO changes appear to be related to changes in the parameterized gravity wave forcing and, hence, depend to some extent on the model's gravity wave drag scheme. Since the source spectrum for gravity wave parameterizations cannot at present be constrained by observations, the choice of spectrum is somewhat arbitrary. In addition, the gravity wave 
source was kept effectively constant in our experiments. The robustness of the parameterized gravity wave feedbacks under climate change is an important issue for future research.

In addition to the changes discussed above, the model predicts substantial changes in the polar regions of the stratosphere in response to changes in SSTs. However, comparison of the temperature response and significance levels for two 15-yr subsets of our 30-yr dataset has shown that these results appear to be robust only away from the polar winter region. There, the interannual variability is too large for 15 -yr simulations to accurately characterize the model response. It was also shown that the Student's $t$ test applied at winter high latitudes can yield misleading signals of statistical significance. Further studies are required to bring clarity to this issue.

Analysis of planetary Rossby waves at middle and high latitudes in the stratosphere has shown very weak changes in upward-propagating planetary wave activity and, consequently, no significant thermal effect in the polar winter stratosphere. However, it is clear from the increase in upwelling in the lower tropical stratosphere that the wave driving of the Brewer-Dobson circulation has increased at low latitudes.

In the combined experiment $\left(2 \times \mathrm{CO}_{2}\right.$ with modified SSTs), the ozone mixing ratio increases by $10 \%-20 \%$ between 30 and $70 \mathrm{~km}$, which is a response to lower temperatures as described by Jonsson et al. (2004). As a result of the modified SSTs, ozone also increases in a thin layer around $75 \mathrm{~km}$ and decreases near the tropical tropopause. The thin layer in the mesosphere results from increased downward transport of atomic oxygen from higher levels in the model. While the relative change in ozone near $75 \mathrm{~km}$ is large, the absolute change is very small. The ozone decrease near the lowlatitude tropopause results primarily from the upward shift of the tropopause, but also reflects an enhanced two-cell diabatic circulation in the lower stratosphere.

The warming of the lower atmosphere leads to more water vapor in the troposphere. There is also a small but statistically significant water vapor increase of $\sim 0.3-0.4$ ppmv in the stratosphere and lower mesosphere, resulting from the warmer (and higher) tropical tropopause, and hence less effective freeze drying of air entering from the troposphere.

This study has several limitations. First, there is no heterogeneous chemistry and hence no severe polar ozone loss. Thus, changes in polar temperatures are only indicative of potential chemical ozone loss in the polar lower stratosphere. This eliminates the ozone radiative feedback that would delay the breakdown of the polar vortex under conditions of high chlorine loading
(Manzini et al. 2003). Second, by forcing the CMAM with SSTs obtained from a coupled (transient) simulation with a tropospheric GCM, any feedback on surface climate arising from stratospheric changes or from interactive ozone is strongly damped. To properly investigate such changes, CMAM would need to be coupled to a dynamical ocean model. On the other hand, the setup in the current study allows a separate attribution of the radiative-photochemical response of the middle atmosphere to $\mathrm{CO}_{2}$ increases, and the dynamical response to changes in tropospheric climate. Finally, by running the CMAM under fixed forcings, and only those associated with $\mathrm{CO}_{2}$ increases, the results do not represent a quantitative prediction of future climate. Rather, they provide an understanding of the response of future climate to certain specific forcings, and the statistical challenges associated with such attribution. Results from these simulations will be important for attributing the behavior of transient simulations performed with CMAM or other CCMs under both greenhouse gas and halogen forcings.

Acknowledgments. Thanks to John Austin for providing comments that led to an improvement in the paper, and to Paul Newman for providing the observational dataset used in Fig. 21 (which is available online at http://code916.gsfc.nasa.gov/People/Newman/ CCMVal/vT_T.html). The authors also thank Norm McFarlane and two anonymous reviewers for helpful comments and suggestions. This work has been supported by the Modelling of Global Chemistry for Climate (GCC) project through grants from the Natural Sciences and Engineering Research Council, the Canadian Foundation for Climate and Atmospheric Sciences, the Canadian Space Agency, and the Meteorological Service of Canada.

\section{REFERENCES}

Akmaev, R. A., and V. I. Fomichev, 1998: Cooling of the mesosphere and lower thermosphere due to doubling of $\mathrm{CO}_{2}$. Ann. Geophys., 16, 1501-1512.

Andrews, D. G., J. R. Holton, and C. B. Leovy, 1987: Middle Atmosphere Dynamics. Academic Press, 489 pp.

Austin, J., and Coauthors, 2003: Uncertainties and assessments of chemistry-climate models of the stratosphere. Atmos. Chem. Phys., 3, 1-27.

Beagley, S. R., J. de Grandpré, J. N. Koshyk, N. A. McFarlane, and T. G. Shepherd, 1997: Radiative-dynamical climatology of the first-generation Canadian middle atmosphere model. Atmos.-Ocean, 35, 293-331.

Beig, G., and Coauthors, 2003: Review of mesospheric temperature trends. Rev. Geophys., 41, 1015, doi:10.1029/ 2002RG000121.

Boer, G. J., G. Flato, and D. Ramsden, 2000: A transient climate change simulation with greenhouse gas and aerosol forcing: 
Projected climate to the twenty-first century. Climate Dyn., 16, 427-450.

Butchart, N., and A. A. Scaife, 2001: Removal of chlorofluorocarbons by increased mass exchange between the stratosphere and troposphere in a changing climate. Nature, 410, 799-802. , J. Austin, J. R. Knight, A. A. Scaife, and M. L. Gallani, 2000: The response of the stratospheric climate to projected changes in the concentrations of the well-mixed greenhouse gases from 1992 to 2051. J. Climate, 13, 2142-2159.

_- and Coauthors, 2006: Simulation of anthropogenic change in the strength of the Brewer-Dobson circulation. Climate Dyn., 27, 727-741.

Cubasch, U., and Coauthors, 2001: Projections of future climate change. Climate Change 2001: The Scientific Basis, J. T. Houghton et al., Eds., Cambridge University Press, 525-582. de Grandpré, J., J. W. Sandilands, J. C. McConnell, S. R. Beagley, P. C. Croteau, and M. Y. Danilin, 1997: Canadian middle atmosphere model: Preliminary results from the chemical transport module. Atmos.-Ocean, 35, 385-431.

— , S. R. Beagley, V. I. Fomichev, E. Griffioen, J. C. McConnell, A. S. Medvedev, and T. G. Shepherd, 2000: Ozone climatology using interactive chemistry: Results from the Canadian middle atmosphere model. J. Geophys. Res., 105, 26 475-26 491.

Eyring, V., and Coauthors, 2006: Assessment of temperature, race species, and ozone in chemistry-climate model simulations of the recent past. J. Geophys. Res., 111, D22308, doi:10.1029/ $2006 J D 007327$.

Fomichev, V. I., J.-P. Blanchet, and D. S. Turner, 1998: Matrix parameterization of the $15 \mu \mathrm{m} \mathrm{CO} \mathrm{CO}_{2}$ band cooling in the middle and upper atmosphere for variable $\mathrm{CO}_{2}$ concentration. J. Geophys. Res., 103, 11 505-11 528.

— W. W. Ward, S. R. Beagley, C. McLandress, J. C. McConnell, N. A. McFarlane, and T. G. Shepherd, 2002: Extended Canadian middle atmosphere model: Zonal-mean climatology and physical parameterizations. J. Geophys. Res., 107, 4087, doi:10.1029/2001JD000479.

—, C. Fu, J. de Grandpré, S. R. Beagley, V. P. Ogibalov, and J. C. McConnell, 2004: Model thermal response to minor radiative energy sources and sinks in the middle atmosphere. $J$. Geophys. Res., 109, D19107, doi:10.1029/2004JD004892.

Gettelman, A., P. M. D. Forster, M. Fujiwara, Q. Fu, H. Vomel, L. K. Gohar, C. Johanson, and M. Ammerman, 2004: Radiation balance of the tropical tropopause layer. J. Geophys. Res., 109, D07103, doi:10.1029/2003JD004190.

Grooß, J.-U., and J. M. Russell III, 2005: Technical note: A stratospheric climatology for $\mathrm{O}_{3}, \mathrm{H}_{2} \mathrm{O}, \mathrm{CH}_{4}, \mathrm{NO}_{x}, \mathrm{HCl}$ and $\mathrm{HF}$ derived from HALOE measurements. Atmos. Chem. Phys., 5, 2797-2807.

Haynes, P. H., C. J. Marks, M. E. McIntyre, T. G. Shepherd, and K. P. Shine, 1991: On the downward control of extratropical diabatic circulations by eddy-induced mean zonal forces. $J$. Atmos. Sci., 48, 651-679.

Horinouchi, T., and Coauthors, 2003: Tropical cumulus convection and upward-propagating waves in middle-atmospheric GCMs. J. Atmos. Sci., 60, 2765-2782.

Jonsson, A. I., J. de Grandpré, V. I. Fomichev, J. C. McConnell, and S. R. Beagley, 2004: Doubled $\mathrm{CO}_{2}$-induced cooling in the middle atmosphere: Photochemical analysis of the ozone radiative feedback. J. Geophys. Res., 109, D24103, doi:10.1029/ 2004JD005093.

Manzini, E., B. Steil, C. Brühl, M. A. Giorgetta, and K. Krüger, 2003: A new interactive chemistry-climate model. 2: Sensitivity of the middle atmosphere to ozone depletion and increase in greenhouse gases and implications for recent stratospheric cooling. J. Geophys. Res., 108, 4429, doi:10.1029/ 2002JD002977.

McLandress, C., and J. F. Scinocca, 2005: The GCM response to current parameterizations of nonorographic gravity wave drag. J. Atmos. Sci., 62, 2394-2413.

_ and V. I. Fomichev, 2006: Amplification of the mesospheric diurnal tide in a doubled $\mathrm{CO}_{2}$ atmosphere. Geophys. Res. Lett., 33, L06808, doi:10.1029/2005GL025345.

Mertens, C. J., and Coauthors, 2004: SABER observations of mesospheric temperatures and comparisons with falling sphere measurements taken during the 2002 summer MaCWAVE campaign. Geophys. Res. Lett., 31, L03105, doi:10.1029/ 2003GL018605.

Newman, P. A., E. R. Nash, and J. E. Rosenfield, 2001: What controls the temperature of the Arctic stratosphere during spring? J. Geophys. Res., 106, 19 999-20 010.

Plumb, R. A., and J. Eluszkiewicz, 1999: The Brewer-Dobson circulation: Dynamics of the tropical upwelling. J. Atmos. Sci., 56, 868-890.

Ramaswamy, V., and Coauthors, 2001: Stratospheric temperature trends: Observations and model simulations. Rev. Geophys., 39, 71-122.

Randel, W., and Coauthors, 2004: The SPARC intercomparison of middle-atmosphere climatologies. J. Climate, 17, 986-1003.

Reichler, T., M. Dameris, and R. Sausen, 2003: Determining the tropopause height from gridded data. Geophys. Res. Lett., 30, 2042, doi:10.1029/2003GL018240.

Rind, D., J. Lerner, J. Perlwitz, C. McLinden, and M. Prather, 2002: Sensitivity of tracer transports and stratospheric ozone to sea surface temperature patterns in the doubled $\mathrm{CO}_{2}$ climate. J. Geophys. Res., 107, 4800, doi:10.1029/2002JD002483. , J. Perlwitz, P. Lonergan, and J. Lerner, 2005: AO/NAO response to climate change. 2: Relative importance of lowand high-latitude temperature changes. J. Geophys. Res., 110, D12108, doi:10.1029/2004JD005686.

Scaife, A. A., J. Austin, N. Butchart, S. Pawson, M. Keil, J. Nash, and I. N. James, 2000: Seasonal and interannual variability of the stratosphere diagnosed from UKMO TOVS analyses. Quart. J. Roy. Meteor. Soc., 126, 2585-2604.

Schmidt, H., and Coauthors, 2006: The HAMMONIA chemistry climate model: Sensitivity of the mesopause region to the 11-year solar cycle and $\mathrm{CO}_{2}$ doubling. J. Climate, 19, 39033931.

Scinocca, J. F., and N. A. McFarlane, 2004: The variability of modeled tropical precipitation. J. Atmos. Sci., 61, 1993-2015.

Scott, R. K., and P. H. Haynes, 1998: Internal interannual variability of the extratropical stratospheric circulation: The lowlatitude flywheel. Quart. J. Roy. Meteor. Soc., 124, 2149-2173. , and _ 2000: Internal vacillations in stratosphere-only models. J. Atmos. Sci., 57, 3233-3250.

Seidel, D. J., R. J. Ross, and J. K. Angell, 2001: Climatological characteristics of the tropical tropopause as revealed by radiosondes. J. Geophys. Res., 106, 7857-7878.

Semeniuk, K., and T. G. Shepherd, 2001: Mechanisms for tropical upwelling in the stratosphere. J. Atmos. Sci., 58, 3097-3115.

Shaw, T. A., and T. G. Shepherd, 2007: Angular momentum conservation and gravity wave drag parameterization: Implications for climate models. J. Atmos. Sci., 64, 190-203.

Shepherd, T. G., and T. A. Shaw, 2004: The angular momentum constraint on climate sensitivity and downward influence in the middle atmosphere. J. Atmos. Sci., 61, 2899-2908.

Shine, K. P., and Coauthors, 2003: A comparison of model- 
simulated trends in stratospheric temperatures. Quart. J. Roy. Meteor. Soc., 129, 1565-1588.

Sigmond, M., P. C. Siegmund, E. Manzini, and H. Kelder, 2004: A simulation of the separate climate effects of middleatmospheric and tropospheric $\mathrm{CO}_{2}$ doubling. J. Climate, 17, 2352-2367.

Soden, B. J., D. L. Jackson, V. Ramaswamy, M. D. Schwarzkopf, and X. Huang, 2005: The radiative signature of upper tropospheric moistening. Science, 310, 841-844.

Taguchi, M., and S. Yoden, 2002: Internal interannual variability of the troposphere-stratosphere coupled system in a simple global circulation model. Part II: Millennium integrations. $J$. Atmos. Sci., 59, 3037-3050.

WCRP-SPARC, 2002: SPARC intercomparison of middle atmo- sphere climatologies. Tech. Rep. 3, World Climate Research Program-Stratospheric Processes and their Role in Climate, Geneva, Switzerland, 96 pp.

WMO, 2003: Scientific assessment of ozone depletion: 2002. Tech. Rep. 47, Global Ozone Research and Monitoring Project, World Meteorological Organization, Geneva, Switzerland, $498 \mathrm{pp}$.

Yin, J. H., 2005: A consistent poleward shift of the storm tracks in simulations of 21st century climate. Geophys. Res. Lett., 32, L18701, doi:10.1029/2005GL023684.

Yoden, S., M. Taguchi, and Y. Naito, 2002: Numerical studies on time variations of the troposphere-stratosphere coupled system. J. Meteor. Soc. Japan, 80, 811-830. 